\begin{tabular}{|l|l|}
\hline Title: & \multicolumn{1}{|c|}{$\begin{array}{c}\text { Experimental Investigation on Punching Strength and Deformation } \\
\text { Capacity of Shear-Reinforced Slabs }\end{array}$} \\
\hline Authors: & Lips S., Fernández Ruiz M., Muttoni A. \\
\hline Published in: & ACI Structural Journal \\
\hline $\begin{array}{l}\text { Volume: } \\
\text { Pages: }\end{array}$ & $\begin{array}{l}\text { Vol. } 109 \\
\text { pp. } 889-900\end{array}$ \\
\hline Country: & USA \\
\hline Year of publication: & 2012 \\
\hline Type of publication: & Peer reviewed journal article \\
\hline
\end{tabular}

Please quote as:

Lips S., Fernández Ruiz M., Muttoni A., Experimental Investigation on Punching Strength and Deformation Capacity of Shear-Reinforced Slabs, ACI Structural Journal, Vol. 109, USA, 2012, pp. 889-900. 


\title{
Experimental Investigation on Punching Strength and Deformation Capacity of Shear-Reinforced Slabs
}

\author{
by Stefan Lips, Miguel Fernández Ruiz, and Aurelio Muttoni
}

\begin{abstract}
This paper presents the results of an extensive experimental campaign on 16 flat-slab specimens with and without punching shear reinforcement. The tests aimed to investigate the influence of a set of mechanical and geometrical parameters on the punching shear strength and deformation capacity of flat slabs supported by interior columns. All specimens had the same plan dimensions of $3.0 \times 3.0 \mathrm{~m}(9.84 \times$ $9.84 \mathrm{ft}$ ). The investigated parameters were the column size (ranging between 130 and $520 \mathrm{~mm}$ [approximately 5 and $20 \mathrm{in}$.]), the slab thickness (ranging between 250 and $400 \mathrm{~mm}$ [approximately 10 and $16 \mathrm{in.}$ ]), the shear reinforcement system (studs and stirrups), and the amount of punching shear reinforcement. Systematic measurements (such as the load, the rotations of the slab, the vertical displacements, the change in slab thickness, concrete strains, and strains in the shear reinforcement) allow for an understanding of the behavior of the slab specimens, the activation of the shear reinforcement, and the strains developed in the shear-critical region at failure. Finally, the test results were investigated and compared with reference to design codes (ACI 318-08 and EC2) and the mechanical model of the critical shear crack theory (CSCT), obtaining a number of conclusions on their suitability.
\end{abstract}

Keywords: critical shear crack theory; deformation capacity; flat slabs; punching shear; shear reinforcement.

\section{INTRODUCTION}

Failures in punching of flat slabs without shear reinforcement develop in a brittle manner with limited deflections and are followed by an almost complete loss of the loadcarrying capacity (Fig. 1). This limits the redistribution of internal forces in case of a local failure, which can potentially lead to a progressive collapse of the entire structure. ${ }^{1}$ Well-designed punching shear reinforcement significantly improves the slab behavior, as it not only increases the punching strength but also the deformation capacity of the structure (Fig. 1). Therefore, its use is encouraged in new design codes, such as the first complete draft of the new fib Model Code 2010. ${ }^{2}$ However, the strength and deformation capacity of shear-reinforced slabs are influenced by several different factors, depending mainly on the governing failure mode of the slab. For slabs complying with typical detailing rules, ${ }^{2}$ three potential failure modes govern ${ }^{3}$ : punching within the shear-reinforced area (Fig. 2(a)), punching outside the shear-reinforced zone (Fig. 2(b)), and failure of the concrete close to the column (Fig. 2(c)). Additionally, depending on the detailing, other failure modes, such as delamination (Fig. 2(d)) or failure between the transverse reinforcement (Fig. 2(e)), can occur. ${ }^{3}$ Also, the flexural capacity (Fig. 2(f)) can govern ${ }^{4}$ for slabs with low flexural reinforcement ratios and large amounts of punching shear reinforcement.

Failure between transverse reinforcements and punching outside the shear-reinforced region are controlled by the shear strength of concrete and can generally be prevented by following certain detailing rules and using a sufficiently large shear-reinforced area.

Research performed by Fernández Ruiz and Muttoni, ${ }^{3}$ Hawkins, ${ }^{5}$ Seible et al., ${ }^{6}$ Van der Voet et al., ${ }^{7}$ Elgabry and Ghali, ${ }^{8}$ Regan and Samadian, ${ }^{9}$ Gomes and Regan, ${ }^{10}$ and Birkle ${ }^{11}$ contributed largely to the understanding and design for punching outside the shear-reinforced area or between transverse reinforcement. For failures within the shearreinforced area and for failures of the compressive struts close to the column, however, the interaction of the concrete and shear reinforcement is more dominant and thus needs to

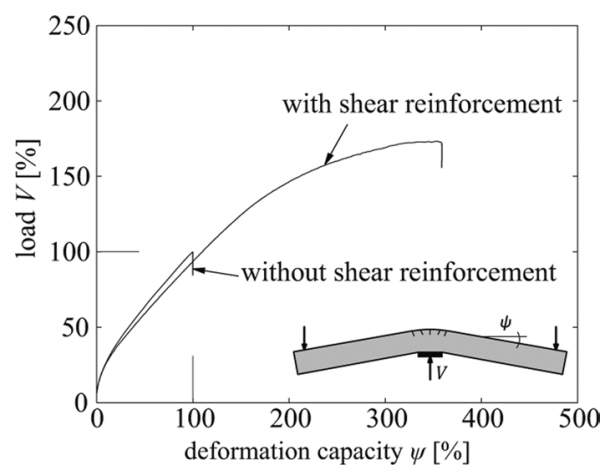

Fig. 1-Relative load-deformation curve for specimens with and without shear reinforcement.

(a)

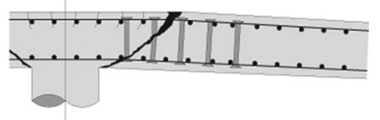

(b)

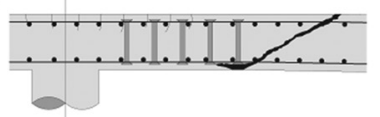

(c)

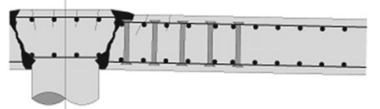

(d)

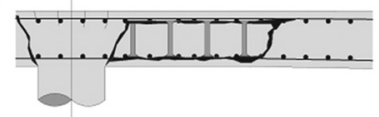

(e)

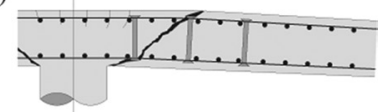

(f)

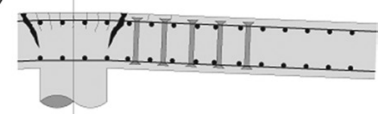

Fig. 2-Potential failure modes: (a) failure within shearreinforced area; (b) failure outside shear-reinforced area; (c) failure close to column by crushing of concrete struts; (d) delamination of concrete core; (e) failure between transverse reinforcement; and (f) flexural failure.

ACI Structural Journal, V. 109, No. 6, November-December 2012.

MS No. S-2011-037.R3 received December 17, 2011, and reviewed under Institute publication policies. Copyright (C) 2012, American Concrete Institute. All rights reserved, including the making of copies unless permission is obtained from the copyright proprietors. Pertinent discussion including author's closure, if any, will be published in the September-October 2013 ACI Structural Journal if the discussion is received by May 1,2013 
ACI member Stefan Lips is a Graduate Research Assistant at the School of Architecture, Civil, and Environmental Engineering (ENAC) of the École Polytechnique Fédérale de Lausanne (EPFL), Lausanne, Switzerland. He received his BS from the University of Applied Sciences Rapperswil, Rapperswil, Switzerland, and his MS from the Georgia Institute of Technology, Atlanta, GA, in 2004 and 2007, respectively. His research interests include punching shear and deformation capacity of reinforced concrete structures.

Miguel Fernández Ruiz is a Lecturer and Research Scientist at EPFL-ENAC. His research interests include the serviceability behavior of structures, bond, shear and punching shear, and the modeling of structural concrete using stress fields.

ACI member Aurelio Muttoni is a Professor and Head of the Structural Concrete Laboratory at EPFL-ENAC. His research interests include the theoretical bases of the design of reinforced concrete structures, shear and punching shear, fiber-reinforced high-strength concrete, soil-structure interaction, and the conceptual design of bridges.

be considered for calculating the punching shear strength. More limited research on these failure modes exists in the literature. In recent years, efforts have been devoted to theoretical and experimental investigations ${ }^{12,13}$ and mechanical models have been developed ${ }^{3,11,14}$ for consistent design against these failure modes. Nevertheless, most code provisions are still based on empirical formulations. ${ }^{15,16}$ One promising approach has been proposed by Fernández Ruiz and Muttoni ${ }^{3}$ which is based on the mechanical model provided by the critical shear crack theory (CSCT). This approach, ${ }^{17}$ which has been adopted in the new fib Model Code 2010, accounts for the various geometrical and mechanical parameters of the slab and shear reinforcement (such as anchorage conditions), and is suitable for a number of punching shear reinforcement systems. ${ }^{18,19}$

In this paper, systematic experimental research on 16 fullscale slab specimens is presented with the aim of investigating the influence of various mechanical and geometrical parameters (thickness, column size, and shear reinforcement systems) on the punching shear strength for failure by crushing of the compression struts or by punching within the shear- reinforced zone. Detailed measurements on the development of strains at the shear reinforcement, the change in slab thickness, or the concrete strains at the shear-critical region allow for an understanding of the differences in the behavior of the slab. Additionally, the obtained results were compared to ACI $318-08^{15}$ and Eurocode 2 (EC2), ${ }^{16}$ as well as the CSCT. ${ }^{3}$ On that basis, the suitability of these approaches is investigated and discussed.

\section{RESEARCH SIGNIFICANCE}

Punching shear reinforcement is an efficient way to increase the strength and deformation capacity of flat slabs and thus increase their safety. Although different shear reinforcement systems and detailing rules may lead to rather different behaviors and strengths, scarce systematic research on this subject can be found in the literature for full-scale specimens. In this paper, the results of an experimental campaign on specimens with thicknesses ranging from 250 to $400 \mathrm{~mm}$ (approximately 10 to 16 in.) and reinforced with stirrups or studs is presented. The detailed measurements performed allow for direct comparisons of the performance of the shear reinforcement and provide an understanding of the influence of various physical parameters on the shear strength and deformation capacity of the members.

\section{Specimens}

\section{EXPERIMENTAL CAMPAIGN}

Table 1 shows the main parameters of the test specimens. All slab specimens had a plan dimension of $3.0 \times 3.0 \mathrm{~m}$ $(9.84 \times 9.84 \mathrm{ft})$ and a constant flexural reinforcement ratio of approximately $1.5 \%$. This reinforcement ratio was chosen to prevent flexural failures. ${ }^{4,20}$ The top and bottom reinforcement layouts were orthogonal and parallel to the slab edge. The spacing of the flexural reinforcement was constant for all specimens and equal to $100 \mathrm{~mm}$ (3.9 in.). The flexural

Table 1-Main parameters of test specimens

\begin{tabular}{|c|c|c|c|c|c|c|c|c|c|}
\hline Specimen & $h, \mathrm{~mm}$ (in.) & $c, \mathrm{~mm}($ in.) & $d, \mathrm{~mm}$ (in.) & $f_{c}, \mathrm{MPa}(\mathrm{psi})$ & $\rho, \%$ & $f_{y}, \mathrm{MPa}(\mathrm{psi})$ & $\rho_{t}, \%$ & $f_{y}, \mathrm{MPa}(\mathrm{psi})$ & System \\
\hline PL1 & $250(9.8)$ & $130 \times 130(5.12 \times 5.12)$ & $193(7.6)$ & $36.2(5250)$ & 1.63 & $583(84.6)$ & - & - & - \\
\hline PL6 & $250(9.8)$ & $130 \times 130(5.12 \times 5.12)$ & $198(7.8)$ & $36.6(5300)$ & 1.59 & $583(84.6)$ & 1.01 & $519(75.3)$ & Studs \\
\hline PV1 $1^{18}$ & $250(9.8)$ & $260 \times 260(10.2 \times 10.2)$ & $210(8.3)$ & $34.0(4900)$ & 1.50 & 709 (102) & - & - & - \\
\hline PL7 & $250(9.8)$ & $260 \times 260(10.2 \times 10.2)$ & $197(7.8)$ & $35.9(5200)$ & 1.59 & $583(84.6)$ & 0.93 & $519(75.3)$ & Studs \\
\hline PL3 & $250(9.8)$ & $520 \times 520(20.5 \times 20.5)$ & $197(7.8)$ & $36.5(5000)$ & 1.59 & $583(84.6)$ & - & - & - \\
\hline PL8 & $250(9.8)$ & $520 \times 520(20.5 \times 20.5)$ & $200(7.9)$ & $36.0(5200)$ & 1.57 & $583(84.6)$ & 0.85 & $519(75.3)$ & Studs \\
\hline PF3 & $250(9.8)$ & $520 \times 520(20.5 \times 20.5)$ & $209(8.2)$ & $37.1(5400)$ & 1.50 & $583(84.6)$ & 0.79 & $536(77.7)$ & Stirrups \\
\hline PL4 & $320(12.6)$ & $340 \times 340(13.4 \times 13.4)$ & $267(10.5)$ & $30.5(4400)$ & 1.58 & $\begin{array}{c}531 \varnothing 20580 \varnothing 26 \\
(77.0 \varnothing 0.884 .1 \varnothing 1.0)\end{array}$ & - & - & - \\
\hline PL5 & $400(15.7)$ & $440 \times 440(17.3 \times 17.3)$ & $353(13.9)$ & $31.9(4650)$ & 1.50 & $580(84.1)$ & - & - & - \\
\hline PL10 & $400(15.7)$ & $440 \times 440(17.3 \times 17.3)$ & $343(13.5)$ & $33.0(4800)$ & 1.55 & $580(84.1)$ & 0.82 & $563(81.7)$ & Studs \\
\hline PF5 & $400(15.7)$ & $440 \times 440(17.3 \times 17.3)$ & $354(13.9)$ & $33.4(4850)$ & 1.50 & $580(84.1)$ & 0.79 & $550(79.8)$ & Stirrups \\
\hline PL11 & $250(9.8)$ & $260 \times 260(10.2 \times 10.2)$ & $201(7.9)$ & $34.2(4950)$ & 1.56 & $554(80.4)$ & 0.23 & $592(85.9)$ & Studs \\
\hline PL12 & $250(9.8)$ & $260 \times 260(10.2 \times 10.2)$ & $201(7.9)$ & $34.6(5000)$ & 1.56 & $554(80.4)$ & 0.47 & $592(85.9)$ & Studs \\
\hline
\end{tabular}



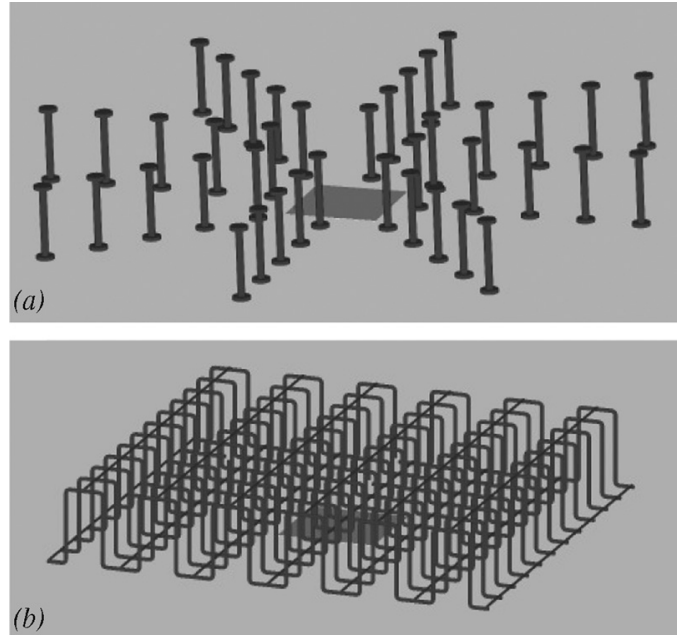

Fig. 3-Investigated punching shear reinforcement systems: (a) corrugated studs; and (b) cages of continuous stirrups.

reinforcement consisted of bars with a diameter of $20 \mathrm{~mm}$ (0.8 in.) for $250 \mathrm{~mm}$ (9.8 in.) thick specimens, an alternate diameter of 20 and $26 \mathrm{~mm}$ ( 0.8 and $1.0 \mathrm{in}$.) for $320 \mathrm{~mm}$ (12.6 in.) thick specimens, and a diameter of $26 \mathrm{~mm}$ (1.0 in.) for $400 \mathrm{~mm}$ (15.7 in.) thick specimens. The longitudinal reinforcement at the compression side was constant for all specimens and consisted of bars with a diameter of $10 \mathrm{~mm}(0.39 \mathrm{in}$.) with a spacing of $100 \mathrm{~mm}$ (3.9 in.) in both directions. For the shear reinforcement, two systems were investigated: corrugated shear studs and cages of continuous stirrups (refer to Fig. 3). The shear studs were arranged radially with constant spacing between studs of a radius according to European practice. Research $^{21,22}$ has shown that this layout provides similar results as an orthogonal layout corresponding to American practice. The number of studs in a row was determined so no punching at the outer perimeter could occur with a spacing between them corresponding to a typical value in practice $\left(s_{1} / d=0.75\right)$. The diameter and number of radii were chosen so all specimens had a shear reinforcement ratio $\rho_{t}$ between 0.79 and $1.01 \%$, except for Specimens PL11 and PL12, for which a quarter-and-a-half of the previous shear reinforcement ratios were used ( $\rho_{t}$ equal to $0.23 \%$ and $0.46 \%$, respectively).

In the case of shear studs, the shear reinforcement ratio $\rho_{t}$ is calculated at a perimeter at $d / 2$ of the edge of the support region

$$
\rho_{t}=\frac{n_{r} \cdot \frac{\pi}{4} \cdot d_{t}^{2}}{s_{1} \cdot(4 c+\pi d)}
$$

where $n_{r}$ is the number of radii of shear reinforcement; $d_{t}$ is the shear reinforcement diameter; $s_{1}$ is the distance between two adjacent reinforcements at the same radius (refer to Fig. 4(a)); $c$ is the side length of the column; and $d$ is the effective depth of the slab.

The cages of continuous stirrups consisted of bent bars $\left(d_{t}\right.$ $=10 \mathrm{~mm}$ [0.39 in.]) that were welded together with straight bars (with a diameter of $6 \mathrm{~mm}[0.24 \mathrm{in}$.$] ) to a cage. The$ spacing between each vertical branch of the stirrups was a constant $100 \mathrm{~mm}$ (3.94 in.), leading to a constant shear reinforcement ratio of $\rho_{t}=0.79 \%$. One cage with dimen- (a)
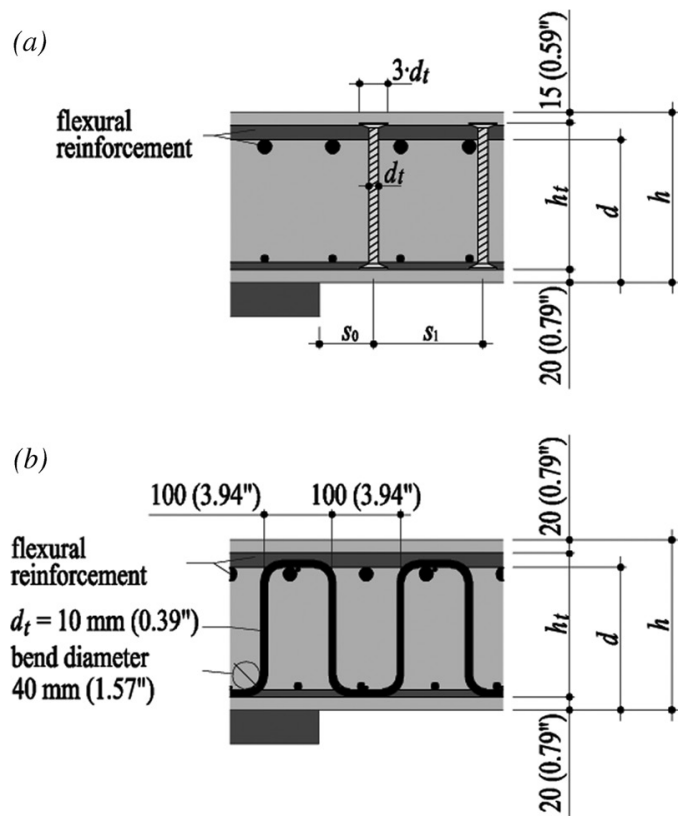

Fig. 4-Details of shear reinforcements: (a) corrugated studs; and (b) cages of continuous stirrups. (Note: Dimensions in $\mathrm{mm}$ [in.].) (a)

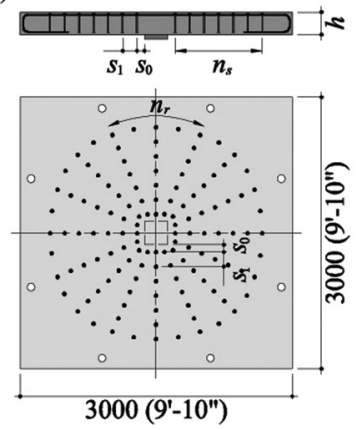

(b)
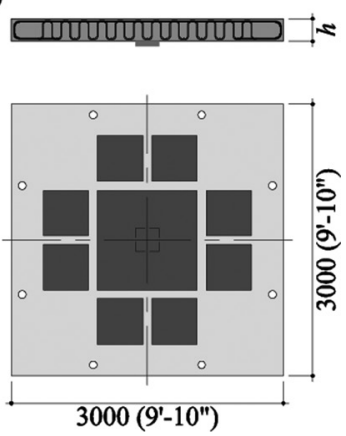

Fig. 5-Placing of shear reinforcement: (a) studs (Specimen PL7 as example); and (b) cages of continuous stirrups (Specimens PF1 to PF5). (Note: Dimensions in mm [in.].)

sions of $1200 \times 1200 \mathrm{~mm}(47.2 \times 47.2 \mathrm{in}$.) was placed in the center of the slab surrounded by eight smaller cages with dimensions of $600 \times 600 \mathrm{~mm}$ ( $23.6 \times 23.6 \mathrm{in}$.) that prevented a failure at the outer perimeter of the shear-reinforced area. Tables 2 and 3 show an overview of the shear reinforcement parameters; Fig. 4 and 5 show the details and distribution of the shear reinforcement.

\section{Materials}

For all specimens, normal-strength concrete with a maximum aggregate size of $16 \mathrm{~mm}$ (0.63 in.) was used. The compressive strength was determined on cylinders with a height of $320 \mathrm{~mm}(12.6 \mathrm{in}$.) and a diameter of $160 \mathrm{~mm}$ (6.3 in.) at 14 days, 28 days, and the day of testing. For the flexural reinforcement, hot-rolled steel with an average yield strength ranging between 531 and $583 \mathrm{MPa}$ (77.0 and $84.6 \mathrm{ksi}$ ) was used. For the punching shear reinforcement, the studs consisted of hot-rolled steel with an average yield strength ranging between 516 and $591 \mathrm{MPa}(74.8$ and $85.7 \mathrm{ksi})$, whereas the stirrups consisted of cold-worked steel with an average yield strength ranging between 536 and $550 \mathrm{MPa}$ 


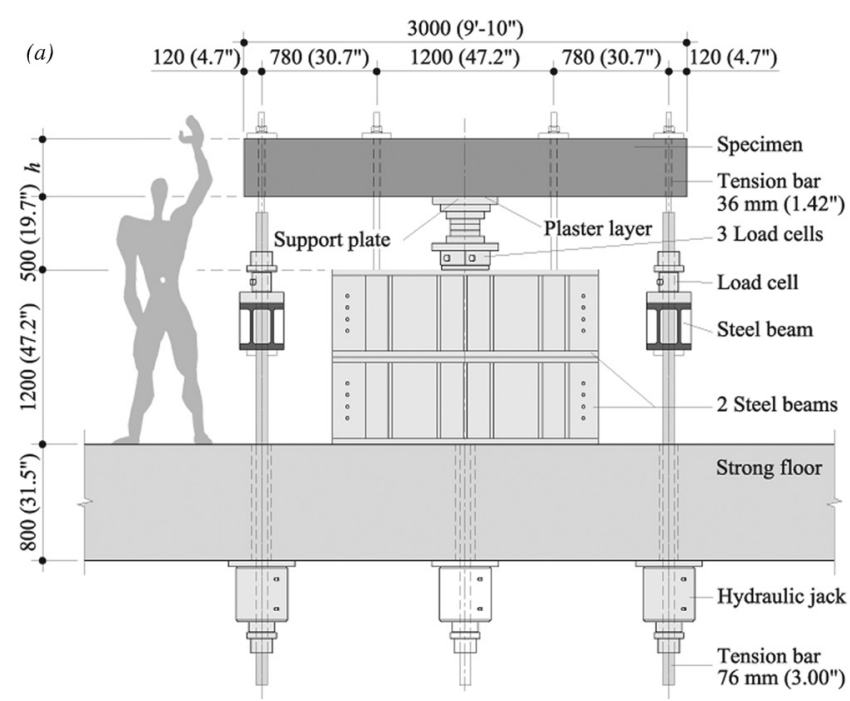

(b)

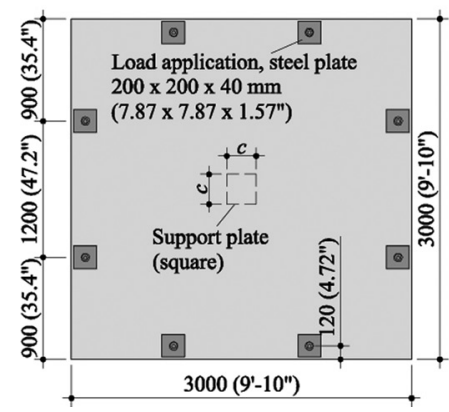

(c)

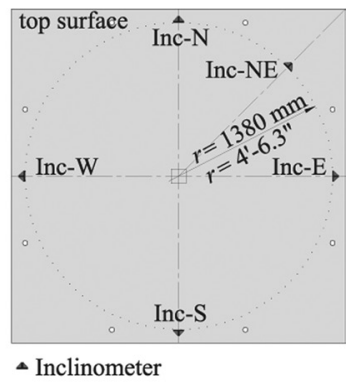

Fig. 6-(a) Drawing of test setup; (b) geometry of test specimen; and (c) location of rotation measurements. (Note: Dimensions in $\mathrm{mm}[\mathrm{ft}$, in.].)

(77.7 and $79.8 \mathrm{ksi}$ ). Details for each specimen can be found in Table 1.

\section{Test setup}

The applied force was introduced by four hydraulic jacks underneath the strong floor (Fig. 6). Four tension bars running through the floor were connected to four steel spreader beams, which distributed the load to eight tension bars. These bars applied the downward force on the top surface of the slab. The slab was supported by a square steel plate corresponding to the column size. Figure 6(a) shows the dimensions of the test setup and Fig. 6(b) shows the load introduction points on the top surface of the slab.

\section{Measurements}

During the tests, various continuous measurements were recorded. Load cells measured the applied load at the hydraulic jacks and the reaction forces at the support. Five inclinometers measured the rotation of the slab. They were arranged on the top surface of the slab at a distance of $1.38 \mathrm{~m}$ $(4.53 \mathrm{ft}$ ) from the center (refer to Fig. 6(c)). Several linear variable displacement transducers (LVDTs) were placed on the top and bottom sides of the slab to measure the vertical displacements. The rotations measured by the inclinometers calculated on the basis of the LVDTs have almost a linear correlation until failure (where the deformation $w$ increases slightly more than proportionally. This will be discussed later in the paper with reference to shear strains developing at the failure region).
Table 2-Parameters of corrugated studs

\begin{tabular}{c|c|c|c|c|c|c|c}
\hline Specimen & $\begin{array}{c}d_{t}, \mathrm{~mm} \\
\text { (in.) }\end{array}$ & $\begin{array}{c}s_{0}, \mathrm{~mm} \\
\text { (in.) }\end{array}$ & $\begin{array}{c}s_{1}, \mathrm{~mm} \\
\text { (in.) }\end{array}$ & $n_{r}$ & $n_{s}$ & $\begin{array}{c}\rho_{t}, \\
\%\end{array}$ & $\begin{array}{c}h_{t}, \mathrm{~mm} \\
\text { (in.) }\end{array}$ \\
\hline PL6 & $14(0.6)$ & $80(3.2)$ & $160(6.3)$ & 12 & 6 & 1.01 & $215(8.5)$ \\
\hline PL7 & $14(0.6)$ & $80(3.2)$ & $160(6.3)$ & 16 & 7 & 0.93 & $215(8.5)$ \\
\hline PL8 & $14(0.6)$ & $80(3.2)$ & $160(6.3)$ & 24 & 7 & 0.85 & $215(8.5)$ \\
\hline PL9 & $18(0.7)$ & $100(3.9)$ & $200(7.9)$ & 16 & 6 & 0.93 & $285(11.2)$ \\
\hline PL10 & $22(0.9)$ & $130(5.1)$ & $260(10.2)$ & 16 & 5 & 0.82 & $365(14.4)$ \\
\hline PL11 & $10(0.4)$ & $80(3.2)$ & $160(6.3)$ & 8 & 7 & 0.23 & $215(8.5)$ \\
\hline PL12 & $10(0.4)$ & $80(3.2)$ & $160(6.3)$ & 16 & 7 & 0.47 & $215(8.5)$ \\
\hline
\end{tabular}

Table 3-Parameters of cages of continuous stirrups

\begin{tabular}{c|c|c|c|c}
\hline Specimen & $d_{t}, \mathrm{~mm}($ in.) & $s_{t}, \mathrm{~mm}(\mathrm{in})$. & $\rho_{t}, \%$ & $h_{t}, \mathrm{~mm}(\mathrm{in})$. \\
\hline PF1-3 & $10(0.4)$ & $100(3.9)$ & 0.79 & $200(7.9)$ \\
\hline PF4 & $10(0.4)$ & $100(3.9)$ & 0.79 & $270(10.6)$ \\
\hline PF5 & $10(0.4)$ & $100(3.9)$ & 0.79 & $345(13.6)$ \\
\hline
\end{tabular}

Additionally, two LVDTs were used to measure the change of the thickness of the slab by using a small rod, which was fixed at the bottom surface, put through a hole in the slab (with a diameter of $8 \mathrm{~mm}[0.31 \mathrm{in}$.$] ), and connected to the$ LVDT fixed on the top surface of the slab. Omega-shaped extensometers with a measuring length of 50 and $100 \mathrm{~mm}$ ( 2.0 and 3.9 in.) measured the surface deformation of the concrete at the top and bottom surfaces of the slab. They were placed in axial and diagonal directions on the top and bottom surfaces of the slab. Additionally, 12 strain gauges measured the strains in the punching shear reinforcement. After the test, the slab specimens were cut in half along the north-south axis to analyze the punching surface in detail.

\section{TEST RESULTS}

The crack pattern and punching zone after failure can be seen in the drawings of the cut sections in Fig. 7. Except Specimen PL8, which underwent large deformation without failure, all slab specimens failed in punching. The inclination of the failure surface was rather steep for members with large amounts of shear reinforcement and particularly for specimens with studs. For lower amounts of shear reinforcement and especially for specimens with cages of stirrups, the angle of the failure surface was somewhat flatter (with values of approximately 45 degrees; refer to Reference 3 ) and the critical shear crack crossed two or three rows of shear reinforcement.

The different performance of the specimens with respect to the strength and rotation capacity can be analyzed by means of their load-rotation curves. Figure 8 presents the measured load-rotation curves for all specimens, whereas Fig. 9 shows the normalized load-rotation curves of selected specimens to investigate the individual effects of several parameters. The vertical axis (strength) is normalized to account for column size, depth of the member, and concrete compressive strength. The horizontal value accounts for the critical shear crack width and roughness. ${ }^{23}$

\section{Performance of shear reinforcement}

Figure 9(a) shows the performance of the shear reinforcement systems. Shear reinforcement clearly increases the 
punching strength and the rotation capacity. In comparison to the reference Specimen PV1 ${ }^{18}$ without shear reinforcement, Specimens PF2 (with stirrups) and PL7 (with studs) reached a punching strength of $161 \%$ and $182 \%$, respectively, and a rotation capacity of $220 \%$ and $421 \%$, respectively. Additionally, Fig. 9(a) illustrates that the increase in strength and rotation capacity depends somewhat on the shear reinforcement system with a better performance of studs (due to enhanced anchorage conditions).

\section{Column size}

Figure 8(c) shows the influence of the column size. As one can expect, the larger the column size, the larger the punching strength and the rotation capacity of the slab-column connection. In comparison to Specimen PL7 (reference with studs), Specimen PL6 (small column with studs) reached only $77 \%$ of the punching strength and $58 \%$ of the rotation capacity. In contrast, Specimen PL8 (large column with studs) reached its flexural capacity and no punching failure occurred despite large rotations (after large plastic deformations, the test was stopped before a flexural failure occurred). By normalizing the diagram, as shown in Fig. 9(b), the normalized strength of PL8 is smaller than the strength of PL7, as flexural strength governed. In contrast, the normalized strength of PL6 is approximately the same as the normalized strength of PL7, despite the smaller perimeter.

\section{Slab thickness}

Figure 9(c) shows the influence of the slab thickness. It illustrates that because the three normalized load-rotation curves nearly coincide, the strength develops approximately proportional to the normalization parameter $b_{0} d$ and the rotation capacity is inversely proportional to the normalization parameter $d$. This indicates a similar influence of size as for specimens without shear reinforcement ${ }^{23}$ (compare Fig. 8(d) to (e) and (f)).

\section{Amount of shear reinforcement}

Figure 9(d) shows the effects of different amounts of shear reinforcement. Even a small amount of shear reinforcement increases the punching strength and rotation capacity of the slab. Specimen PL11 reached a punching strength of $121 \%$ of the strength of the reference Specimen PV1 and a rotation capacity of $157 \%$ of the rotation of PV1. By doubling the amount of shear reinforcement, the punching strength and rotation capacity can be further increased. Specimen PL12 reached a punching strength of $168 \%$ of the strength of Specimen PV1 and a rotation capacity of $289 \%$ of the rotation of PV1. Afterward, if the reinforcement ratio is further increased, the punching strength does not significantly increase. This can be explained because the failure mode changes between Specimens PL12 and PL7. While PL12 had a failure within the shear-reinforced area, PL7 had a failure by crushing of the concrete strut close to the column. Consequently, a further increase of the amount of shear reinforcement also leads to crushing of the concrete strut, so it will not result in a significantly higher punching strength or a significantly larger rotation capacity.

\section{Shear deformations at column face}

Figure 10 shows the normalized load-deformation curve for shear deformations near the column face. The shear deformations were determined from the measured vertical displacements at the bottom side of the slab, as shown in Fig. 10(e) (the difference between displacement at Point $\mathrm{A}$ and the

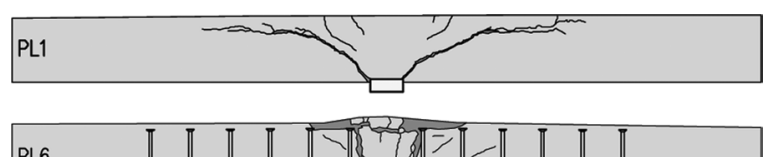

PL6
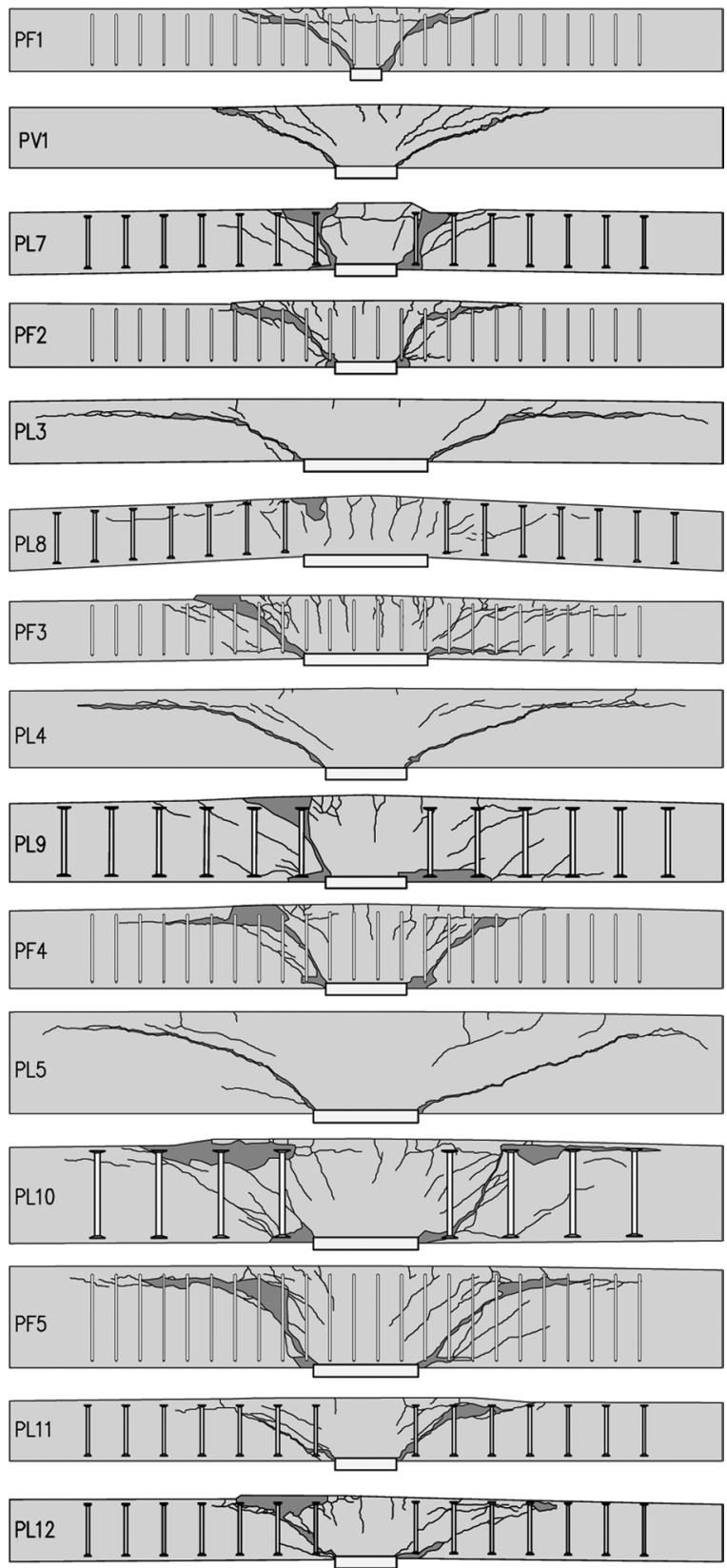

Fig. 7-Cracking pattern after saw cut.

extension of secant between Points B and C). Figure 10(a) illustrates the effects of shear reinforcement on the shear deformations. Large shear deformations occur only if shear reinforcement is used. Additionally, it can be observed that the maximum shear deformation depends on the shear reinforcement system. Slabs with studs lead to larger shear deformations than slabs with stirrups, which is consistent with the observed difference in the normalized strength. Figure 10(b) illustrates the effects of the column size. The smaller the column size, the larger the shear deformations. It can be noted that Specimen PL8, which had a large column $(c / d=2.60)$ and by which no punching failure occurred, the shear deformations are visibly smaller than for PL6, which 
(a)

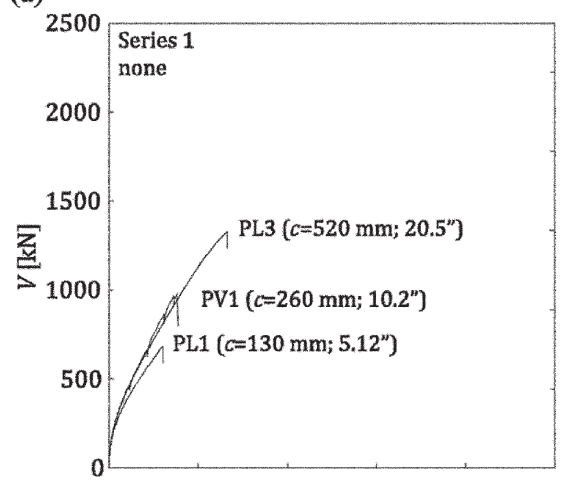

(d)

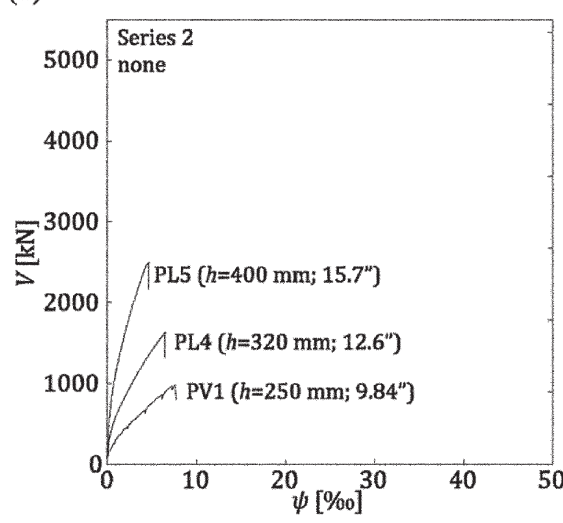

(b)

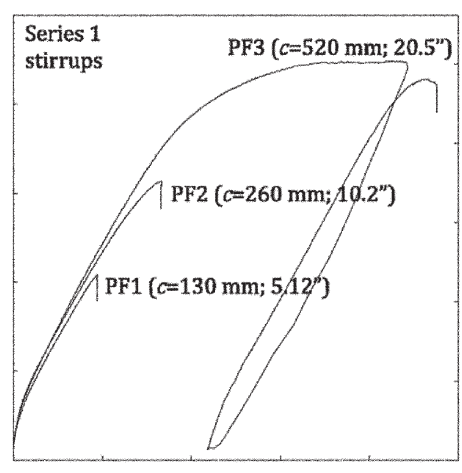

(e)

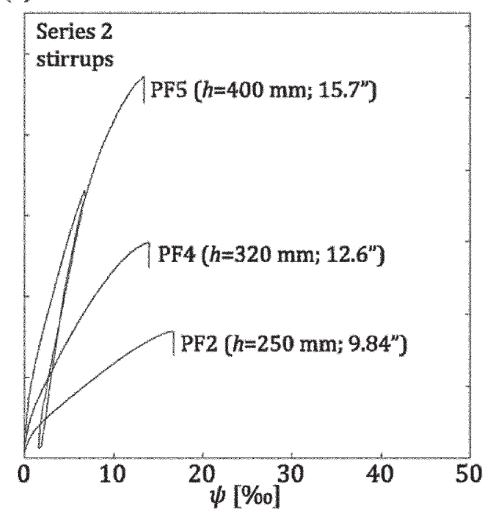

(c)

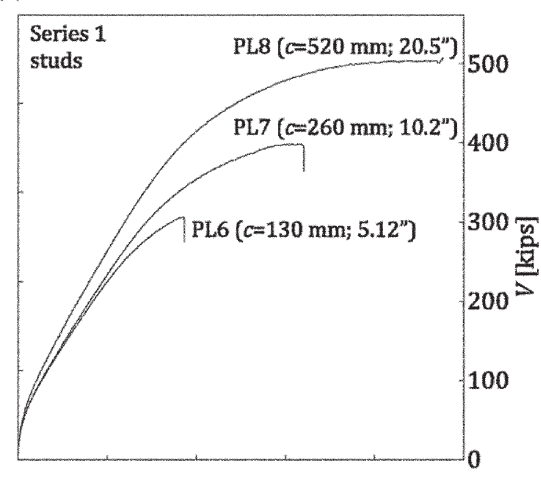

(f)

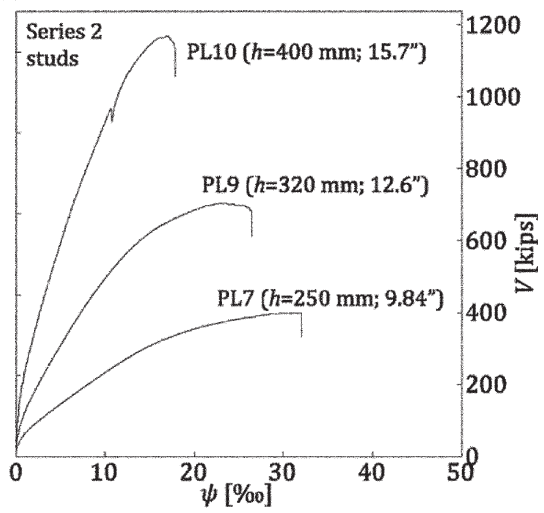

(g)

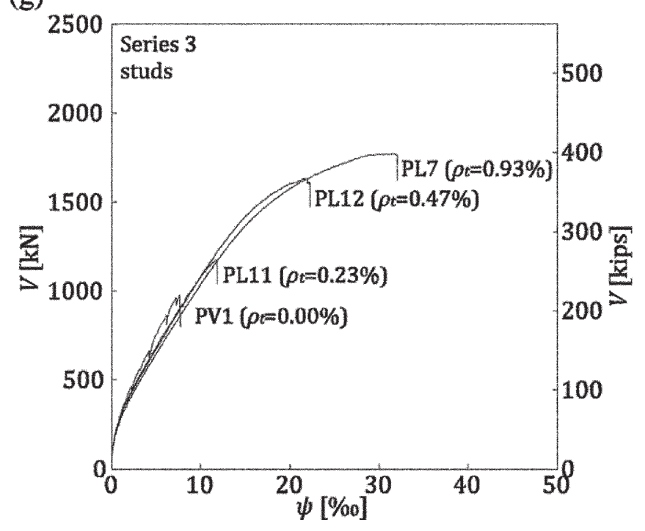

Fig. 8-Load-rotation curves of all tested specimens: (a) to (c) varying column size; $(d)$ to $(f)$ varying thickness; and $(g)$ varying shear reinforcement ratio.

had a small column $(c / d=0.66)$. Again, this is in agreement with the larger normalized shear strength for specimens with small column sizes. Figure 10(c) illustrates the effects of the slab thickness. The thicker the slab, the lower the normalized shear deformations. This effect is rather limited but again in agreement with the normalized shear strength. Finally, Fig. 10(d) illustrates the effects of the amount of shear reinforcement. Three of the specimens (PV1, PL7, and PL12) exhibit a clear trend with increasing shear deformations for larger normalized shear strength. The fourth specimen (PL11) does not correspond to this tendency, as it showed very significant shear strains; however, it can be noted that a part of these strains was measured during a decay of the applied force (the result at the maximum load level is rather consistent with the other specimens).

\section{Opening of critical shear crack}

The measurement of the change in slab thickness can be interpreted as an indirect measurement of the opening of the critical shear crack $^{3}$ and shows the different behavior of the slab specimens without shear reinforcement, with stirrups, and with studs. Figure 11 shows the change of the slab thickness as a function of the applied load for specimens with the same geometries. The specimen without shear reinforcement (PL5) experiences significant changes in thickness after the first shear crack opens. On the contrary, the shear reinforcement of Specimens PF5 and PL10 controls the opening of this crack as they activate. This is consistent with the CSCT hypothesis ${ }^{3}$ (accounting also for the larger rotations developed at failure for specimens with shear reinforcement). According to this theory, ${ }^{3,23}$ this means that the contribution 
(a)

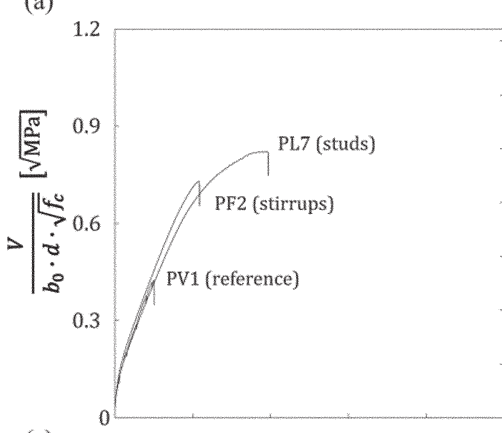

(c)

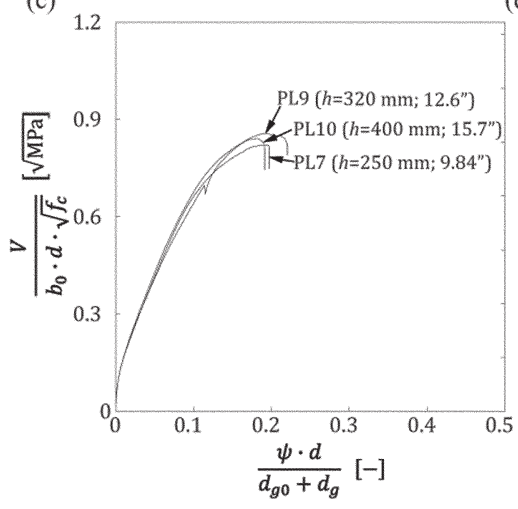

(b)

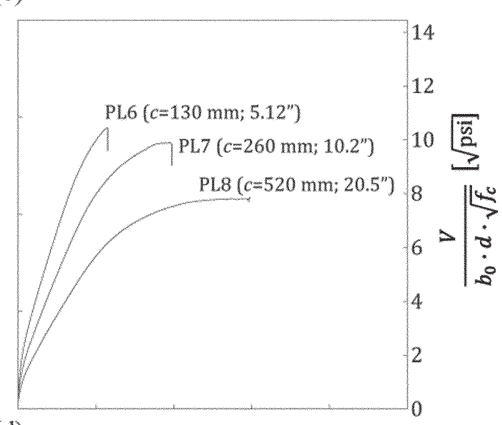

(d)

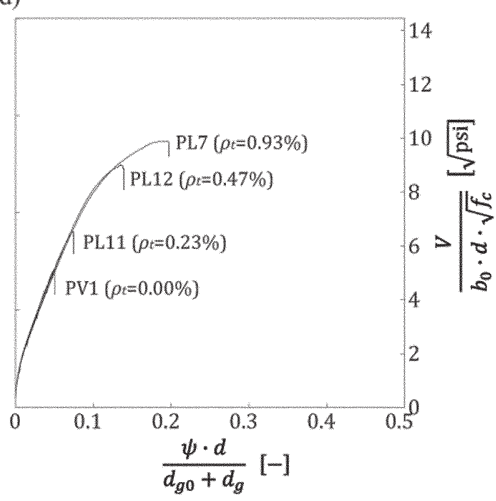

Fig. 9-Normalized load-rotation curves of selected specimens: (a) varying shear reinforcement system; (b) varying column size; (c) varying slab thickness; and $(d)$ varying shear reinforcement ratio.

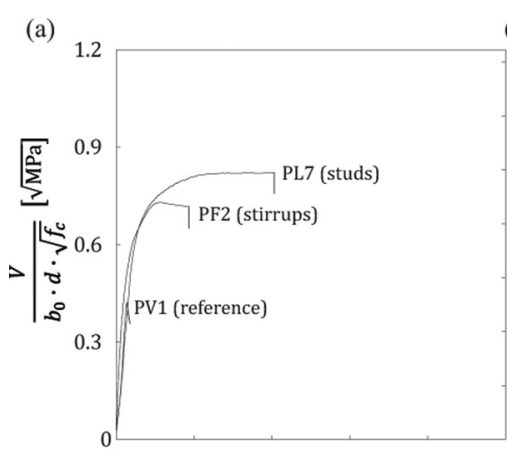

(b)
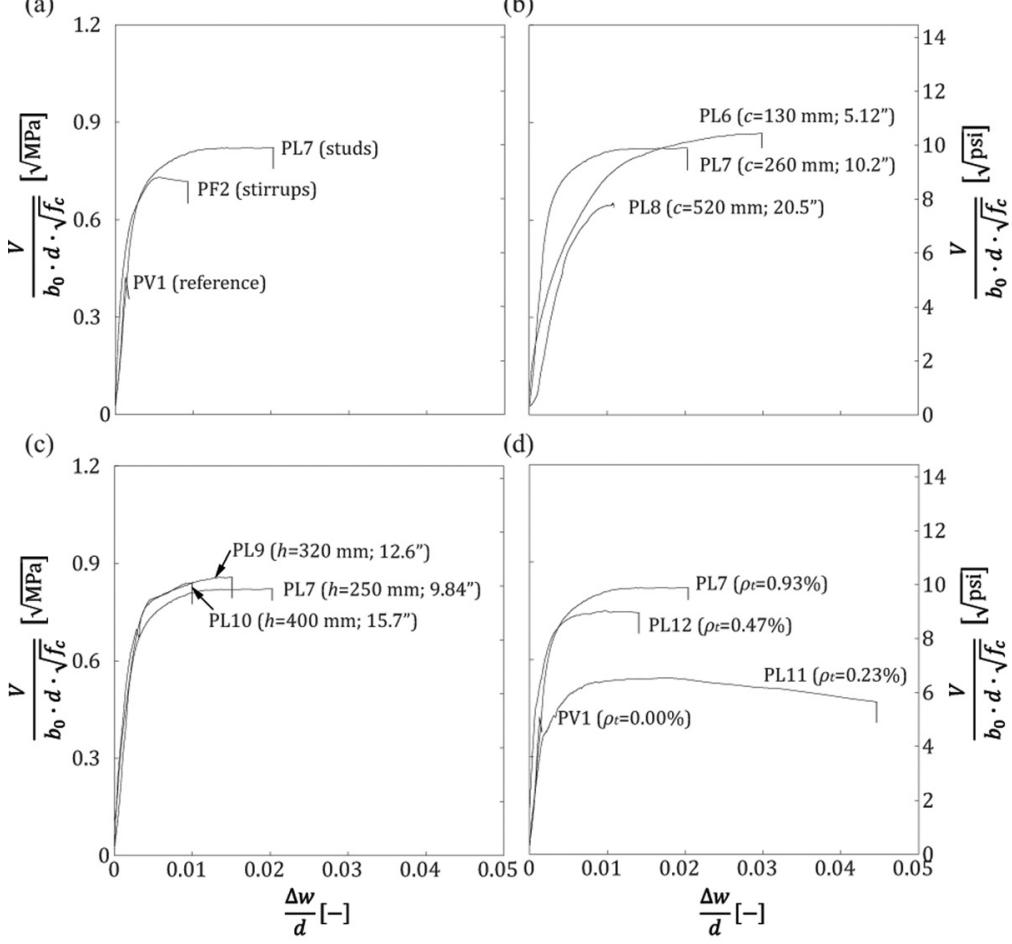

(d)

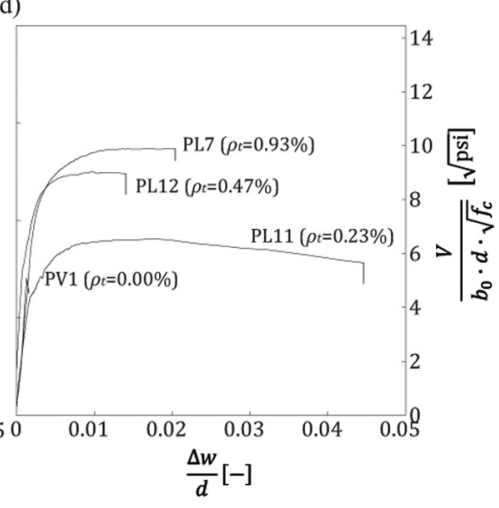

(e)

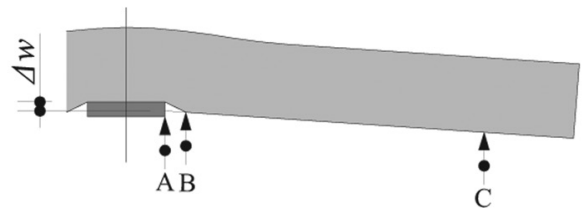

Fig. 10-Normalized shear deformations at column face in function of normalized shear force of selected specimens: (a) varying shear reinforcement system; (b) varying column size; (c) varying slab thickness; (d) varying shear reinforcement ratio; and (e) location of vertical displacement measurements for calculation of shear deformations. 
of concrete at failure is reduced with respect to members without shear reinforcement.

\section{Strains in studs}

The measurements of the local strain in the studs near the top surface of the slab at the first and second perimeters of the studs are illustrated in Fig. 12, which shows the loadstrain curve for a slab with: (a) a large (Specimen PL7; $\rho_{t}$ $=0.93 \%$ ) amount of shear reinforcement; and (b) a small (Specimen PL12; $\rho_{t}=0.47 \%$ ) amount of shear reinforcement. Although in the case of Specimen PL7, both the first and second perimeters reach their yielding strain near failure, the local strains remain in a small range $\left(\varepsilon_{s}<1 \%\right)$. In contrast, the studs in the slab with a lower amount of shear reinforcement (Specimen PL12) behave differently. While the stud in the first perimeter did not reach the yielding strain, the stud in the second perimeter underwent large deformations just before failure. This difference in the behavior of the two slab speci-
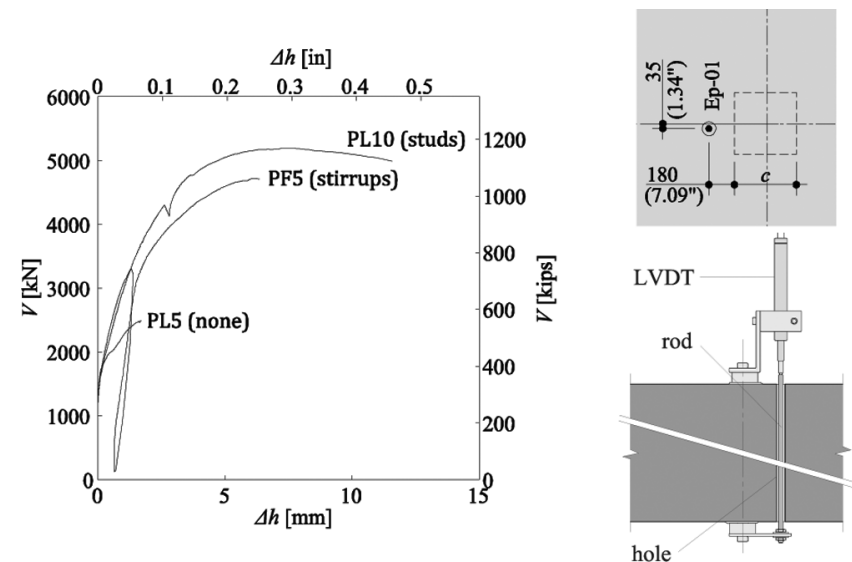

Fig. 11-Curve load-change in slab thickness. (Note: Dimensions in mm [in.].) mens can be explained by the different failure modes. While Specimen PL7 had a failure by crushing of the concrete strut close to the column (Fig. 2(c) and 8), Specimen PL12 had a failure within the shear-reinforced area (Fig. 2(a) and 8). For the specimen developing punching within the shear-reinforced zone, the critical shear crack opening increases from the bottom (close to the column and the first shear reinforcement) to the top surface (close to the second shear reinforcement) (refer to Fig. 2(a)). This experimental result is clearly in agreement with the CSCT hypothesis. ${ }^{3}$ With respect to specimens failing by crushing of concrete struts, the first shear reinforcement is activated at failure due to the formation of a plastic shear band (Fig. 2(c)). Again, this is in agreement with the test measurements. (a)

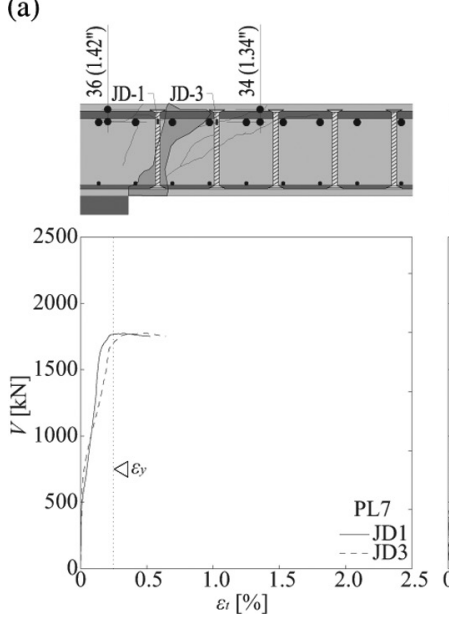

(b)

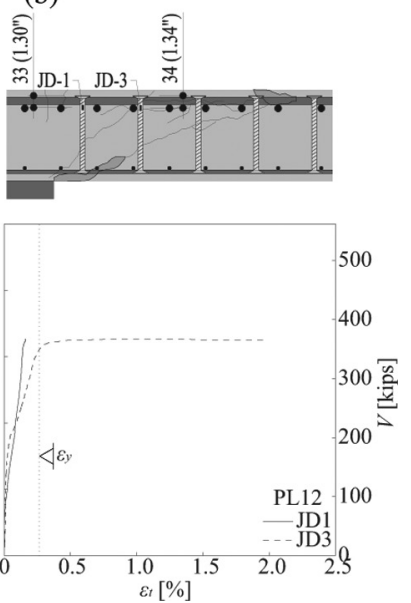

Fig. 12-Load steel-strain curve for slabs with: (a) large amount of shear reinforcement (Specimen PL7); and (b) small amount of shear reinforcement (Specimen PL12). (Note: Dimensions in mm [in.].)
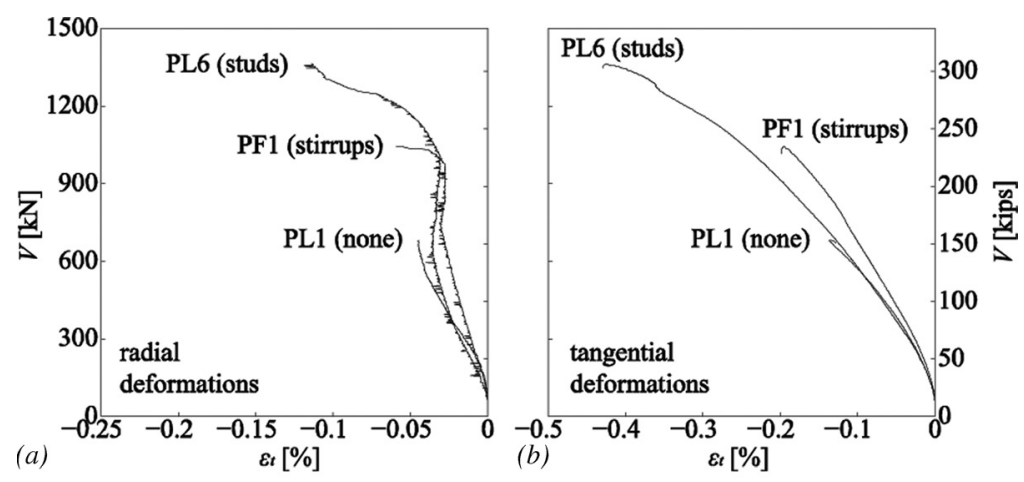

(c)

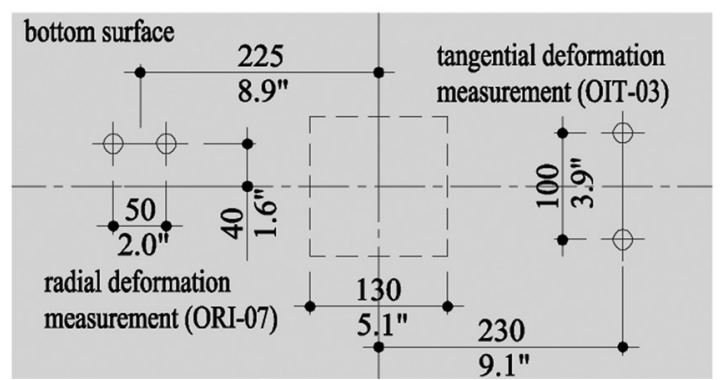

Fig. 13-Load-deformation curve of bottom surface in: (a) radial direction; (b) tangential direction; and (c) positions of surface deformation measurements. (Note: Dimensions in mm [in.].) 
Table 4-Comparison of test results

\begin{tabular}{|c|c|c|c|c|c|c|}
\hline Specimen & $\begin{array}{l}V_{R, \text { test }}, \mathrm{kN} \\
\text { (kips) }\end{array}$ & $\begin{array}{c}\psi_{R, \text { test }}, \\
\% \text { oo }\end{array}$ & $\begin{array}{c}V_{R, \text { test }} l \\
V_{\text {flex }}\end{array}$ & $\begin{array}{l}V_{R, \text { test }} l \\
V_{R, A C I}\end{array}$ & $\begin{array}{l}V_{R, \text { test }} l \\
V_{R, E C}\end{array}$ & $\begin{array}{c}V_{R, \text { test }} / \\
V_{R, C S C T}\end{array}$ \\
\hline PL1 & $682(153)$ & 6.0 & 0.34 & 1.37 & 0.86 & 1.06 \\
\hline PL6 & 1363 (306) & 18.6 & 0.66 & 1.30 & 1.41 & 1.02 \\
\hline PF1 & 1043 (234) & 9.5 & 0.49 & 1.32 & 1.17 & 0.83 \\
\hline $\mathrm{PV} 1^{18}$ & 974 (219) & 7.6 & 0.35 & 1.27 & 0.96 & 1.05 \\
\hline PL7 & 1773 (399) & 32.0 & 0.81 & 1.23 & 0.94 & 1.09 \\
\hline PF2 & $1567(352)$ & 16.7 & 0.69 & 1.46 & 0.90 & 1.02 \\
\hline PL3 & 1324 (298) & 13.2 & 0.52 & 1.16 & 1.06 & 1.12 \\
\hline PL8 & $2256(507)$ & - & 0.87 & - & - & - \\
\hline PF3 & $2242(504)$ & 46.8 & 0.82 & 1.21 & $(0.82)$ & 1.03 \\
\hline PL4 & $1625(365)$ & 6.5 & 0.41 & 1.36 & 1.06 & 1.11 \\
\hline PL9 & 3132 (704) & 26.2 & 0.79 & 1.29 & 1.03 & 1.06 \\
\hline PF4 & 2667 (600) & 14.0 & 0.65 & 1.39 & 0.84 & 0.94 \\
\hline PL5 & $2491(560)$ & 4.7 & 0.34 & 1.18 & 0.99 & 1.00 \\
\hline PL10 & 5193 (1167) & 18.0 & 0.73 & 1.26 & 1.00 & 1.05 \\
\hline PF5 & 4717 (1060) & 13.4 & 0.64 & 1.45 & 0.87 & 1.02 \\
\hline PL11 & 1176 (264) & 11.9 & 0.55 & 1.08 & 1.03 & 1.04 \\
\hline PL12 & 1633 (367) & 22.0 & 0.77 & 1.12 & 1.05 & 1.05 \\
\hline \multicolumn{4}{|c|}{ Average } & 1.28 & 1.01 & 1.03 \\
\hline \multicolumn{4}{|c|}{ Coefficient of variation } & 0.084 & 0.141 & 0.065 \\
\hline
\end{tabular}

\section{Deformations at critical shear region}

Figure 13 shows the surface deformations of the bottom surface in the radial (a) and tangential (b) directions of the slab specimens with the same geometry but different shear reinforcement-Specimen PL1 (none), PL6 (studs), and PF1 (stirrups). The radial strains of the three specimens develop similarly at the beginning, with stabilized or even decreasing strains when the load level is increased with respect to the one leading to punching for the reference specimen (PL1). After formation of the critical shear crack, the radial strains of Specimens PL6 and PF1 remain approximately constant prior to the punching moment, at which the radial strains again significantly increase. This means that the shear reinforcement was effective in controlling the opening of the critical shear crack (which otherwise would have led to decompression of the soffit of the slab ${ }^{23}$ ). The tangential strains of the three specimens increase continuously with a similar trend prior to punching.

\section{THEORETICAL ANALYSIS}

For this discussion, the test results will be compared to design codes (ACI $318-08^{15}$ and EC2 ${ }^{16}$ ) and the CSCT. ${ }^{3}$ The formulations and assumptions for these calculation methods are presented in the Appendix*, whereby only the formulation of a failure within the shear-reinforced area and the formulation of the maximum punching strength (crushing of the concrete strut) are considered.

Table 4 summarizes the measured punching strength and maximum rotation at failure. Additionally, it compares the experimentally obtained punching strength to the calculated

\footnotetext{
*The Appendix is available at www.concrete.org in PDF format as an addendum to the published paper. It is also available in hard copy from ACI headquarters for a fee equal to the cost of reproduction plus handling at the time of the request.
}
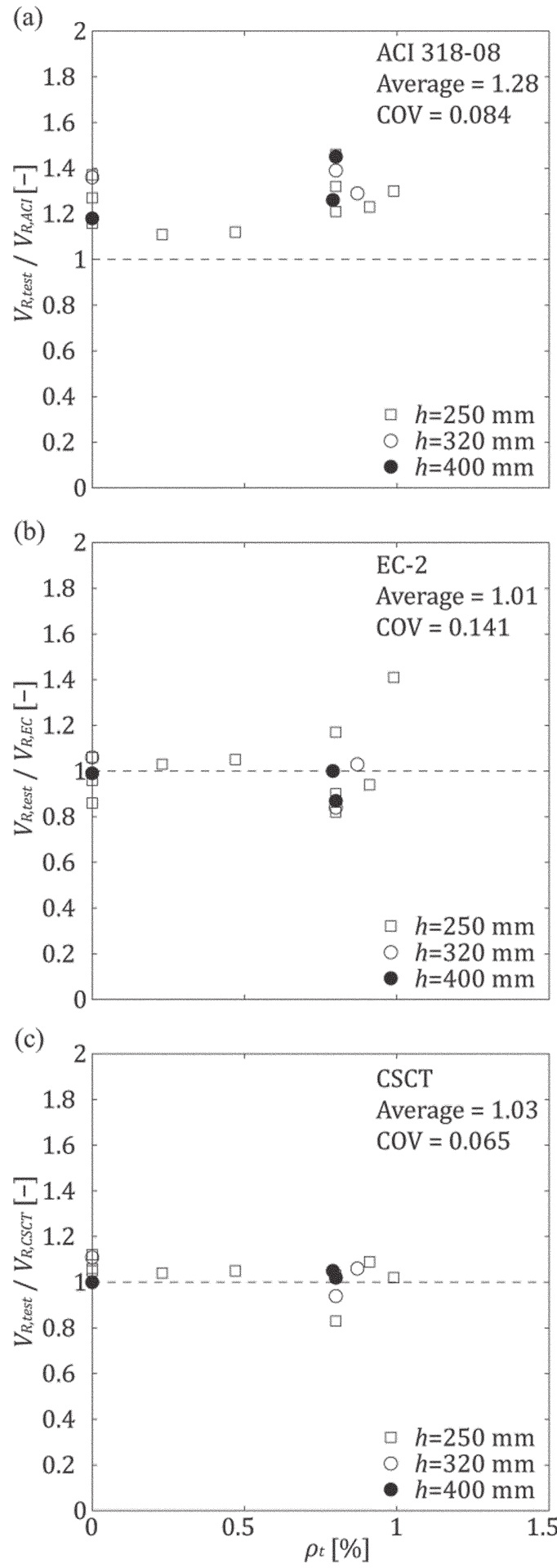

Fig. 14-Comparison between measured and calculated punching strength: (a) ACI 318-08 ${ }^{15}$; (b) EC2 $2^{16}$; and (c) CSCT. ${ }^{3}$ (Note: $1 \mathrm{~mm}=0.039 \mathrm{in}$.)

punching strength, except for Specimen PL8, which did not fail in punching. In the case of EC2 ${ }^{16}$ Specimen PF3 was also excluded from the calculation of the average and coefficient of variation (COV) because the strength is (according to $\mathrm{EC} 2^{16}$ ) controlled by the flexural capacity and not the calculated punching strength. The ratios of the experimental and theoretical punching strength are also illustrated in Fig. 14. Values greater than 1.0 correspond to safe estimates. The relatively simple approach of ACI $318-08^{15}$ leads to some- 
(a)

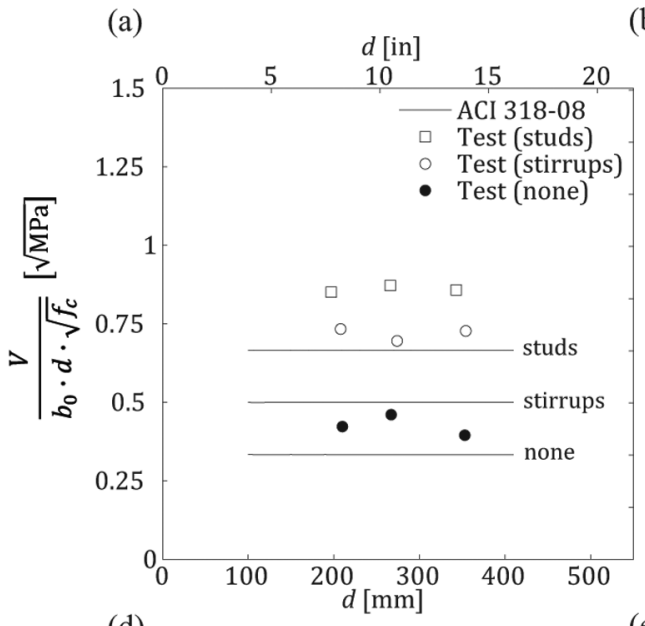

(d)

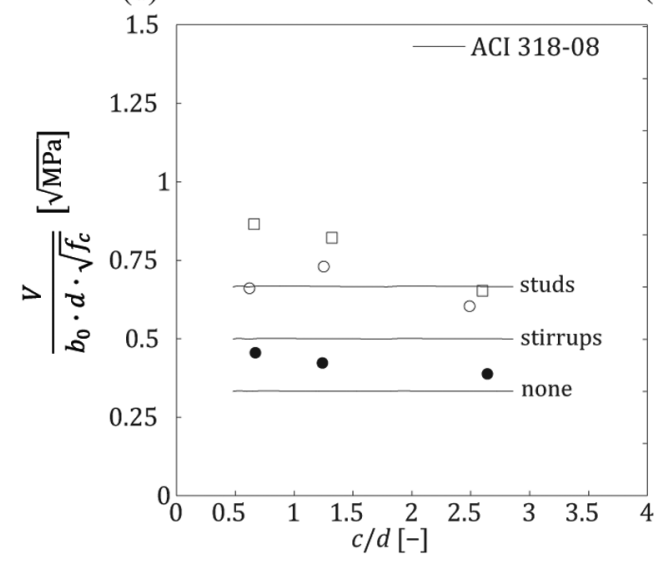

(g)

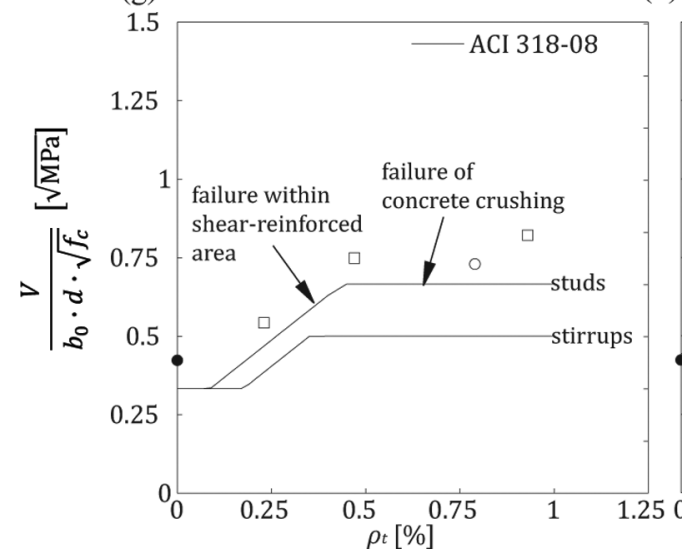

(b)

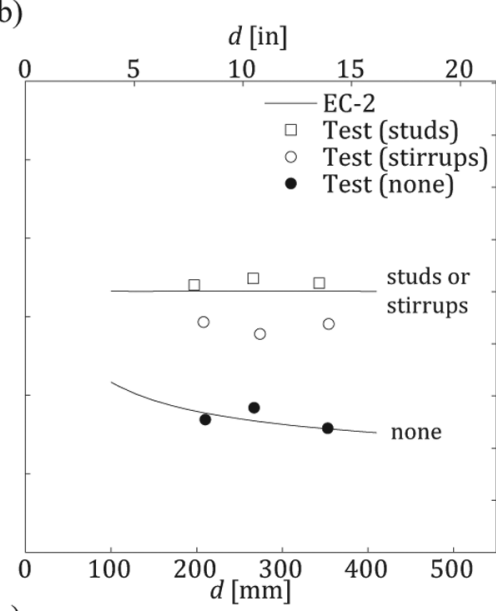

(e)

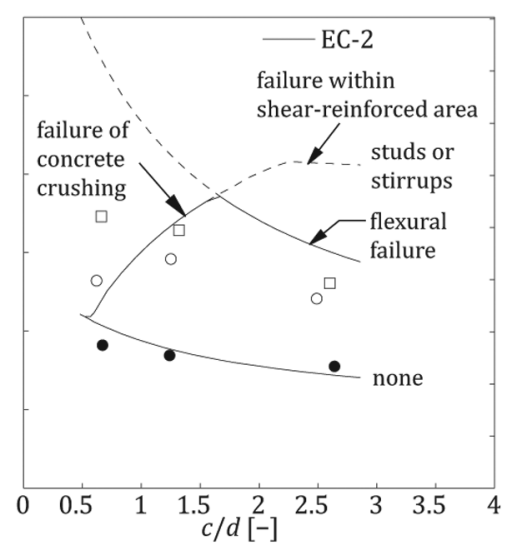

(h)

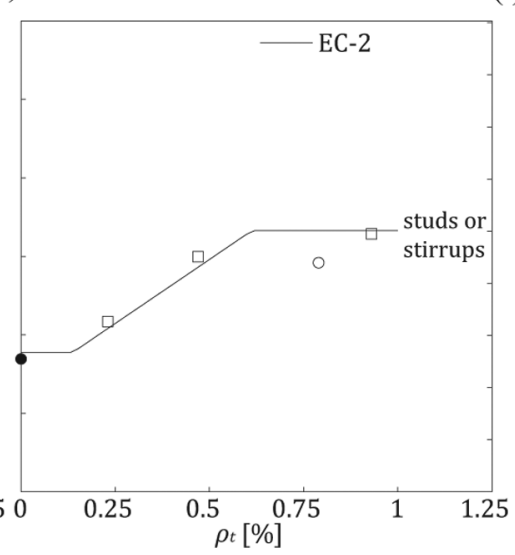

(c)

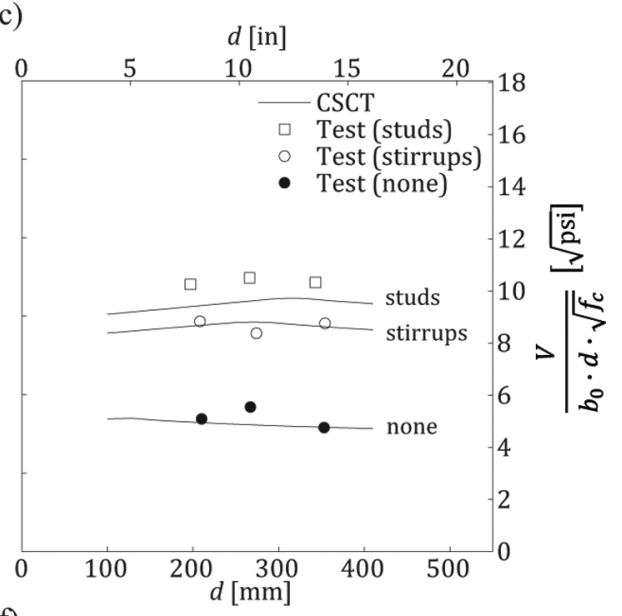

(f)

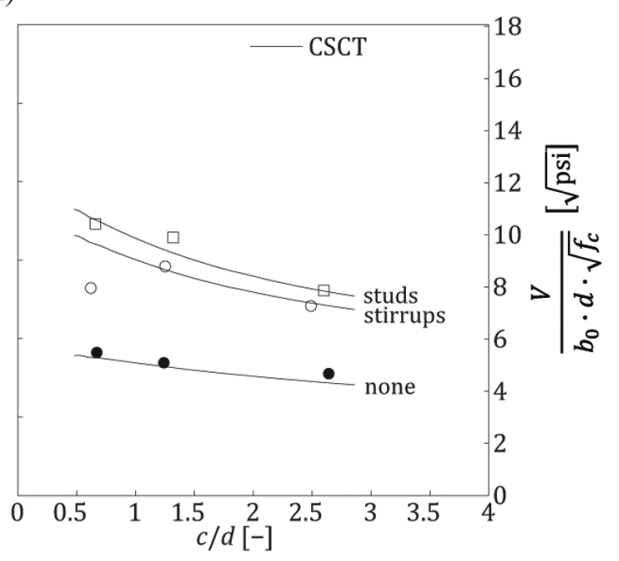

(i)

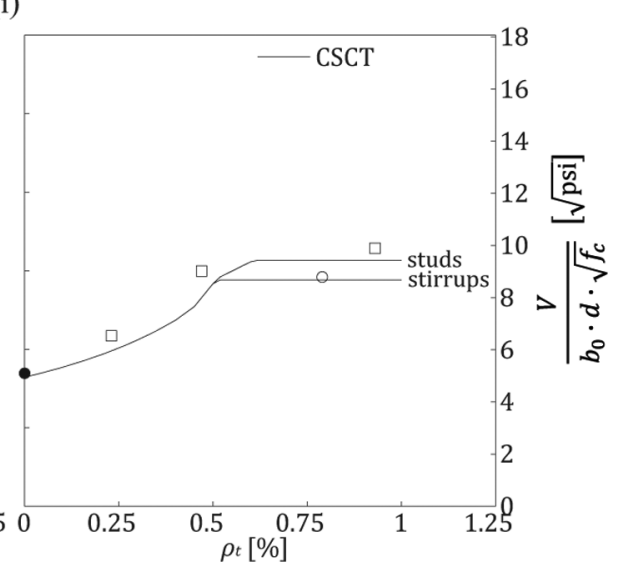

Fig. 15-Comparison between measured and calculated punching strength as function of: $(a)$ to $(c)$ effective depth $\mathrm{d} ;(d)$ to $(f)$ column size to effective depth ratio c/d; and $(g)$ to $(i)$ shear reinforcement ratio $\rho_{\mathrm{t}}$.

what scattered results (but the safest on average), although certain detailing rules are not completely fulfilled (refer to Appendix for further explanation). $\mathrm{EC} 2^{16}$ is more scattered than ACI $318-08^{15}$ and has a lower average value, potentially leading to unsafe predictions of the punching shear strength. The $\mathrm{CSCT}^{3}$ leads to a rather low scatter of the test results and leads to the best estimates with respect to the punching strength. The average value of the measured to the predicted strength is 1.03 and the $\mathrm{COV}$ is $6.5 \%$. These values (average and COV) are in agreement with previous research. ${ }^{3}$

To gain a better understanding of the performance of these design models, the influence of several different parameters was analyzed. Figure 15 shows the punching strength as a function of various parameters, whereby the following assumptions were made: the concrete compression strength was chosen as $33.5 \mathrm{MPa}$ (4.86 ksi; average of the tests), the yielding strength of the flexural reinforcement was chosen as $575 \mathrm{MPa}(83.4 \mathrm{ksi}$; average of the tests), the yielding strength of the shear reinforcement was chosen as $550 \mathrm{MPa}$ (79.8 ksi; average of the tests), the shear reinforcement was chosen as $0.9 \%$ if not varied, the effective depth was chosen as $210 \mathrm{~mm}$ (8.27 in.) if not varied, and the ratio of the column size to the effective depth was chosen as 1.24 if not varied. Figure 15(a) to (c) shows the punching strength as a function of the effective depth d. ACI $318-08^{15}$ neglects this influence, which is rather 
inconsistent for members without shear reinforcement, as discussed elsewhere. ${ }^{4,23,24}$ With respect to shear-reinforced members, the influence of the size effect is more moderate, which is correctly acknowledged by the three approaches. It can be noted that a difference in strength between studs and stirrups can clearly be appreciated. EC $2^{16}$ neglects this fact, which contributes somewhat to its scatter. Figure $15(\mathrm{~d})$ to (f) shows the normalized punching strength as a function of the ratio of the column size to the effective depth, $c / d$. An interesting fact is that all three models result in very different normalized functions that each predict a different behavior. ACI 318-08 ${ }^{15}$ accounts for the $c / d$ only in the perimeter of the critical section $b_{0}$. Therefore, the normalized strength is always constant. This approach leads to safe results in comparison to the test results of all specimens except Specimen PL8 (it might thus be potentially unsafe for large column sizes). The variation of the $c / d$ ratio illustrates that the approach of EC2, ${ }^{16}$ based on a beam analogy, is not suitable for the calculation of the maximum punching strength. This observation is consistent with conclusions previously drawn by other researchers. ${ }^{13,17}$ Problems mainly appear for $c / d$ ratios greater than 1.5 . In this range, $\mathrm{EC} 2{ }^{16}$ clearly overestimates the punching strength and the only limitations are either the calculated flexural capacity (the formulation for the calculation of the flexural capacity is given in the Appendix) or the punching strength calculated for a failure within the shear-reinforced area, which depends on the amount of shear reinforcement. Thus, this approach leads to potentially rather unsafe designs, especially for slabs with large flexural capacities and $c / d$ ratios in combination with a large amount of shear reinforcement. In contrast to $\mathrm{EC} 2^{16}$, the $\mathrm{CSCT}^{3}$ predicts smaller normalized strength for larger $c / d$ ratios. It seems to work well, except for Specimen PF1, which had a very small column $(c / d=0.62)$. It can be noted that such sizes are beyond the hypotheses of the theory, but it could be corrected by considering a variable (steeper) angle of the critical shear crack.

Figure $15(\mathrm{~g})$ through (i) shows the normalized punching strength as a function of the shear reinforcement ratio $\rho_{t}$. All three models show good agreement for the estimate of the failure mode and failure load. The best agreements are again obtained by the models that distinguish between studs and stirrups for calculating the maximum punching shear strength.

\section{CONCLUSIONS}

Sixteen full-scale slab specimens with and without shear reinforcement were tested. The objective was to investigate the influence of several parameters, such as the thickness, column size, and type and amount of shear reinforcement on the punching strength and rotation capacity of flat slabs. Therefore, the focus was set on the failure close to the support region and the failure within the shear-reinforced area. The measurements of this experimental campaign and the comparison to design approaches show that:

1. The crushing of the concrete strut is significantly dependent on the detailing rules of shear reinforcement (for instance, the anchorage properties, spacing, or distance to the supported area).

2. Experimental measurements on shear reinforcement stresses at failure show that they may be well below the yield strength, contrary to what is proposed in some codes of practice, such as ACI 318-08. ${ }^{15}$

3. Compared to the test results, ACI $318-08^{15}$ generally leads to conservative results. The newly implemented increase of the strength in the case of studs in ACI 318-08 ${ }^{15}$ seems to be reasonable (although the test specimens do not fulfill the design rules entirely).

4. Compared to the test results, EC2 ${ }^{16}$ potentially leads to unsafe designs if crushing of the concrete strut governs. This can be particularly relevant in the case of large column sizes, for which the difference between the calculated and the experimentally obtained punching strength can be significant.

5. The performed tests consistently confirm the hypotheses and results of the $\mathrm{CSCT}^{3}$ with respect to the investigated failure modes (punching within the shear-reinforced area and crushing of concrete struts). This theory provides a sound approach, accounting for various physical and geometrical parameters within the limits of validity of the hypothesis of the theory.

6. Shear reinforcement allows the critical shear crack to develop larger widths than for members without transverse reinforcement (as predicted by the $\mathrm{CSCT}^{3}$ ). According to the CSCT, this implies that the contribution of concrete to the punching strength at failure diminishes with respect to members without punching shear reinforcement.

7. The test results show that the influence of the size and slenderness effect on members with punching shear reinforcement failing by crushing of concrete struts (maximum punching shear strength) is similar to that of members without shear reinforcement.

8. Detailed measurements of shear deformations in the failure region showed that this strain is not negligible for shear-reinforced members and increases significantly with shear strength.

\section{NOTATION}

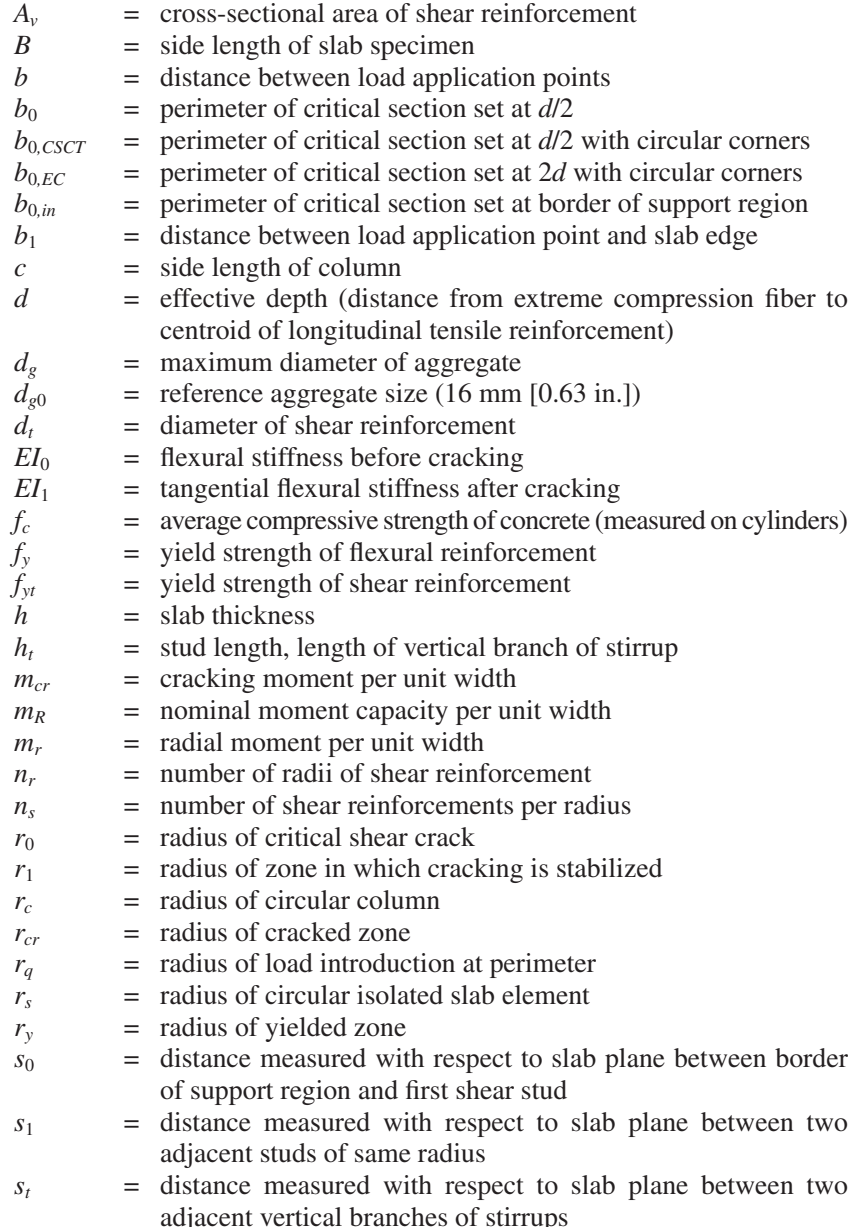


$V_{\text {flex }}=$ shear force associated with flexural capacity of slab specimen

$V_{R} \quad=$ punching shear strength

$V_{R, A C I}=$ punching shear load calculated according to ACI 318-08

$V_{R, C S C T}=$ punching shear load calculated according to CSCT

$V_{R, E C}=$ punching shear load calculated according to EC2

$V_{R, \text { test }}=$ measured punching shear strength

$w$

$\chi_{T S}$

$\Delta h$

$\Delta w$

$\varepsilon$

$=$ vertical displacement

$=$ decrease in curvature due to tension stiffening

$=$ change in slab thickness

$=$ vertical displacement due to shear deformations at column face

$=$ surface deformation

$=$ strain in shear reinforcement

$=$ yielding strain of shear reinforcement

$=$ coefficient accounting for different shear reinforcing systems

$=$ flexural reinforcement ratio

$=$ shear reinforcement ratio

$=$ shear reinforcement stress

$=$ slab rotation

$=$ measured rotation at failure

\section{ACKNOWLEDGMENTS}

The authors wish to express their gratitude and sincere appreciation to the Swiss National Science Foundation (Project No. 121566) for financing this research. Additionally, the authors would like to thank the punching shear reinforcement manufacturer Fischer-Rista AG for allowing the publication of certain experimental data.

\section{REFERENCES}

1. Fernández Ruiz, M.; Fürst, A.; Guandalini, S.; Hunkeler, F.; Moser, K.; Muttoni, A.; and Seiler, H., "Sécurité structurale des parkings couverts (Structural Safety of Parking Garages)," Documentation SIA D0226, Zurich, Switzerland, 2008, 105 pp. (in French)

2. fib (CEB-FIP), "fib Bulletin 56: Model Code 2010, First Complete Draft," V. 2, Lausanne, Switzerland, Apr. 2010, 288 pp.

3. Fernández Ruiz, M., and Muttoni, A., "Application of Critical Shear Crack Theory to Punching of Reinforced Concrete Slabs with Transverse Reinforcement," ACI Structural Journal, V. 106, No. 4, July-Aug. 2009, pp. 485-494.

4. Guandalini, S.; Burdet, O. L.; and Muttoni, A., "Punching Tests of Slabs with Low Reinforcement Ratios," ACI Structural Journal, V. 106 No. 1, Jan.-Feb. 2009, pp. 87-95.

5. Hawkins, N. M., "Shear Strength of Slabs with Shear Reinforcement," Shear in Reinforced Concrete, SP-42, American Concrete Institute, Farmington Hills, MI, 1974, pp. 785-815.

6. Seible, F.; Ghali, A.; and Dilger, W. H., "Preassembled Shear Reinforcing Units for Flat Plates," ACI Journal, Proceedings V. 77, No. 1, Jan.-Feb. 1980, pp. 28-35.

7. Van der Voet, F.; Dilger, W. H.; and Ghali, A., "Concrete Flat Plates with Well-Anchored Shear Reinforcement Elements," Canadian Journal of Civil Engineering, V. 9, No. 1, 1981, pp. 107-114.

8. Elgabry, A. A., and Ghali, A., "Design of Stud-Shear Reinforcement for Slabs," ACI Structural Journal, V. 87, No. 3, May-June 1990, pp. 350-361.
9. Regan, P. E., and Samadian, F., "Shear Reinforcement against Punching in Reinforced Concrete Flat Slabs," The Structural Engineer, V. 79, No. 10, 2001, pp. 24-31.

10. Gomes, R. B., and Regan, P. E., "Punching Strength of Slabs Reinforced for Shear with Offcuts of Rolled Steel I-Section Beams," Magazine of Concrete Research, V. 51, No. 2, 1999, pp. 121-129.

11. Birkle, G., "Punching of Flat Slabs: The Influence of Slab Thickness and Stud Layout," PhD thesis, University of Calgary, Calgary, AB, Canada, 2004, $152 \mathrm{pp}$

12. Beutel, R., and Hegger, J., "The Effect of Anchorage on the Effectiveness of the Shear Reinforcement in the Punching Zone," Cement and Concrete Composites, V. 24, No. 6, 2002, pp. 539-549.

13. Hegger, J.; Walraven, J. C.; and Häusler, F., "Zum Durchstanzen von Flachdecken nach Eurocode 2 (Punching of Flat Slabs According to Eurocode 2)," Beton- und Stahlbetonbau, V. 105, No. 4, 2010, pp. 206-215. (in German)

14. Dechka, D. C., "Response of Shear-Stud-Reinforced Continuous Slab-Column Frames to Seismic Loads," PhD thesis, University of Calgary, Calgary, AB, Canada, 2001, 472 pp.

15. ACI Committee 318, "Building Code Requirements for Structural Concrete (ACI 318-08) and Commentary," American Concrete Institute, Farmington Hills, MI, 2008, 473 pp.

16. EN 1992-1-1, "Eurocode 2: Design of Concrete Structures-Part 1-1: General Rules and Rules for Buildings," CEN, Brussels, Belgium, 2004, $225 \mathrm{pp}$.

17. Muttoni, A., and Fernández Ruiz, M., "MC2010: The Critical Shear Crack Theory as a Mechanical Model for Punching Shear Design and Its Application to Code Provisions," fib Bulletin 57, Lausanne, Switzerland, 2010, pp. 31-60.

18. Fernández Ruiz, M.; Muttoni, A.; and Kunz, J., "Strengthening of Flat Slabs against Punching Shear Using Post-Installed Shear Reinforcement," ACI Structural Journal, V. 107, No. 4, July-Aug. 2010, pp. 434-442.

19. Fernández Ruiz, M., and Muttoni, A., "Performance and Design of Punching Shear Reinforcing Systems," 3rd International fib Congress, No. 437, Washington, DC, 2010, 15 pp.

20. Dilger, W. H.; Birkle, G.; and Mitchell, D., "Effect of Flexural Reinforcement on Punching Shear Resistance," Punching Shear in Reinforced Concrete Slabs, SP-232, M. A. Polak and ACI Committee 445, eds., American Concrete Institute, Farmington Hills, MI, 2005, pp. 57-74.

21. Birkle, G., and Dilger, W. H., "Shear Strength of Slabs with DoubleHeaded Shear Studs in Radial and Orthogonal Layouts," Thomas T.C. Hsu Symposium: Shear and Torsion in Concrete Structures, SP-265, A. Belarbi, Y. L. Mo, and A. Ayoub, eds., American Concrete Institute, Farmington Hills, MI, 2009, pp. 499-510.

22. Vollum, R. L.; Abdel-Fattah, T.; Eder, M.; and Elghazouli, A. Y., "Design of ACI-Type Punching Shear Reinforcement to Eurocode 2," Magazine of Concrete Research, V. 62, No. 1, 2010, pp. 3-16.

23. Muttoni, A., "Punching Shear Strength of Reinforced Concrete Slabs without Transverse Reinforcement," ACI Structural Journal, V. 105, No. 4 , July-Aug. 2008, pp. 440-450

24. Birkle, G., and Dilger, W. H., "Influence of Slab Thickness on Punching Shear Strength," ACI Structural Journal, V. 105, No. 2, Mar.-Apr. 2008, pp. 180-188. 


\section{APPENDIX}

\section{ACI 318-08 ${ }^{15}$}

According to ACI $318-08^{15}$ the punching strength for failure within the shear-reinforced area can be calculated by adding the concrete and the shear reinforcement contributions, whereby the concrete contribution generally corresponds to the half of the punching strength without shear reinforcement. However, in case of double headed studs, ACI 318-08 ${ }^{15}$ (11.11.5.1) proposes the concrete contribution as $3 / 4$ of the punching strength without shear reinforcement. Thus, the punching strength by using stirrups is defined as

$$
\begin{aligned}
& V_{R}=\frac{1}{6} \cdot b_{0} \cdot d \cdot \sqrt{f_{c}}+A_{v} \cdot f_{y t} \cdot \frac{d}{s_{t}} \text { [SI units] } \\
& V_{R}=2 \cdot b_{0} \cdot d \cdot \sqrt{f_{c}}+A_{v} \cdot f_{y t} \cdot \frac{d}{s_{t}} \text { [in.-lb units] }
\end{aligned}
$$

and by using studs as

$$
\begin{aligned}
& \left.V_{R}=\frac{1}{4} \cdot b_{0} \cdot d \cdot \sqrt{f_{c}}+A_{v} \cdot f_{y t} \cdot \frac{d}{s_{1}} \text { [SI units }\right] \\
& V_{R}=3 \cdot b_{0} \cdot d \cdot \sqrt{f_{c}}+A_{v} \cdot f_{y t} \cdot \frac{d}{s_{1}} \text { [in.-lb units] }
\end{aligned}
$$

where $b_{0}$ is a control perimeter set at $d / 2$ of the border of the support region, $d$ is the effective depth of the slab, $f_{c}$ is the compressive strength of concrete, $A_{v}$ is the area of the shear reinforcement at one perimeter, $s_{t}$ is the distance between perimeters of shear reinforcement, and $f_{y t}$ is the yield strength of the shear reinforcement.

The maximum punching strength is defined as the multiple of the punching strength without shear reinforcement. Generally, ACI $318-08^{15}$ proposes the factor to be 1.5 . However, a factor of 2 can be used in case of headed shear studs (ACI 318-08 ${ }^{15} 11.11 .5 .1$ ). It has to be noted that in case of an increase of the maximum punching strength the detailing rules change. In fact, if the 
punching strength is larger than 1.5 times the punching strength without shear reinforcement, the spacing between the studs is limited to $0.5 d$. Although the test specimens have a distance of $0.75 d$ between the studs and thus do not fulfill the detailing rule, this detailing rule has not been considered for the calculations in this paper. Thus, the maximum punching strength of the specimens with stirrups is defined as

$V_{R}=\frac{1}{2} \cdot b_{0} \cdot d \cdot \sqrt{f_{c}} \quad[$ SI units $]$
$V_{R}=6 \cdot b_{0} \cdot d \cdot \sqrt{f_{c}} \quad[$ in.-lb units]

and of the specimens with studs as

$V_{R}=\frac{2}{3} \cdot b_{0} \cdot d \cdot \sqrt{f_{c}}[$ SI units $]$

$V_{R}=8 \cdot b_{0} \cdot d \cdot \sqrt{f_{c}}[$ in.-lb units $]$

where $b_{0}$ is a control perimeter set at $d / 2$ of the border of the support region, $d$ is the effective depth of the slab, and $f_{c}$ is the compressive strength of concrete.

\section{Eurocode $2^{16}$}

Similar to ACI $318-08^{15}$, EC-2 $2^{16}$ proposes a summation of the concrete and the shear reinforcement contribution, whereby the concrete contribution corresponds to $75 \%$ of the punching strength without shear reinforcement. Thus, the punching strength can be calculated by

$$
\begin{array}{ll}
V_{R}=0.75 \cdot\left(0.18 \cdot b_{0, E C} \cdot d \cdot k \cdot\left(100 \cdot \rho \cdot f_{c}\right)^{1 / 3}\right)+A_{v} \cdot f_{y, t e f} \cdot 1.5 \cdot\left(\frac{d}{s_{t}}\right) & {[\text { SI units }]} \\
V_{R}=0.75 \cdot\left(5.0 \cdot b_{0, E C} \cdot d \cdot k \cdot\left(100 \cdot \rho \cdot f_{c}\right)^{1 / 3}\right)+A_{v} \cdot f_{y, e f} \cdot 1.5 \cdot\left(\frac{d}{s_{t}}\right) & {[\text { in.-lb units }]}
\end{array}
$$

where $b_{0, E C}$ is a control perimeter set at $2 d$ of the border of the support region with circular corners, $d$ is the effective depth of the slab, $f_{c}$ is the compressive strength of concrete, $\rho$ is the 
flexural reinforcement ratio, $s_{t}$ is the distance between perimeters of shear reinforcement, $k$ is a factor accounting for the size effect defined as

$$
\begin{array}{ll}
k=1+\sqrt{\frac{200}{d}} \leq 2.0 & \quad[\text { SI units }] \\
k=1+\sqrt{\frac{7.87}{d}} \leq 2.0 & \quad[\text { in.-lb units }]
\end{array}
$$

It has to be noted that in this paper the limitation of $k \geq 2.0$ has not been considered for the comparison to the test results because this limit refers to general design in practice.

$f_{y t, e f}$ is the effective stress in the shear reinforcement defined as

$f_{y, f f}=1.15 \cdot(250+0.25 d) \leq f_{y t} \quad[$ SI units $]$

$f_{y, e f}=1.15 \cdot(36.2+0.92 d) \leq f_{y t} \quad$ [in.-lb units $]$

For the maximum punching strength, EC- $2^{16}$ uses a similar approach as for the calculation of the strength of the compression strut in a beam.

$$
\begin{aligned}
& V_{R}=0.3 \cdot\left(1-\frac{f_{c}}{250}\right) \cdot f_{c} \cdot b_{0, \text { in }} \cdot d \quad[\text { SI units }] \\
& \left.V_{R}=0.3 \cdot\left(1-\frac{f_{c}}{36200}\right) \cdot f_{c} \cdot b_{0, \text { in }} \cdot d \quad \text { [in.-lb units }\right]
\end{aligned}
$$

where $b_{0, i n}$ is a control perimeter set at the border of the support region, $d$ is the effective depth of the slab, $f_{c}$ is the compressive strength of concrete.

\section{$\operatorname{CSCT}^{3}$}

The $\mathrm{CSCT}^{3}$ defines the failure criteria of failure within the shear-reinforced area and of failure of the concrete close to the column as a function of the slab rotation (see Figure A1). For the failure within the shear-reinforced area, the approach adds the concrete strength of a slab without shear reinforcement depending on the crack opening of a critical shear crack $(w \propto \psi \cdot d)$ and the forces 
developed in the shear reinforcement. The force in the shear reinforcement depends on the area of the shear reinforcement and the stresses in the shear reinforcement (Figure A1a).

$$
\begin{array}{ll}
V_{R}(\psi)=\frac{3}{4} \cdot \frac{b_{0, C S C r} \cdot d \cdot \sqrt{f_{c}}}{1+15 \cdot \frac{\psi \cdot d}{d_{g 0}+d_{g}}}+\sum_{i=1}^{n} \sigma_{s t, i}(\psi) \cdot A_{v, i} & {[\text { SI units }]} \\
V_{R}(\psi)=9 \cdot \frac{b_{0, C S c r} \cdot d \cdot \sqrt{f_{c}}}{1+15 \cdot \frac{\psi \cdot d}{d_{g 0}+d_{g}}}+\sum_{i=1}^{n} \sigma_{s, i}(\psi) \cdot A_{v, i} & {[\text { in.lb units }]}
\end{array}
$$

where $\psi$ is the rotation of the slab, $d_{g}$ is the maximum aggregate size, $d_{g 0}$ is a reference aggregate size (equal to $16 \mathrm{~mm} ; 0.63$ in) and $b_{0, C S C T}$ is the control perimeter set at $d / 2$ of the border of the support region and circular at the corners, $d$ is the effective depth of the slab, $f_{c}$ is the compressive strength of concrete, $A_{v}$ is the cross-sectional area of the shear reinforcement (intersected by a failure surface at $45^{\circ}$ ), and $\sigma_{s t}(\psi)$ is the stress in the reinforcement developed for a given rotation. For this it is assumed that a critical shear crack that crosses the shear reinforcement opens proportional to the product of the slab rotation and its effective depth ${ }^{3}$.

With respect to the assessment of the crushing shear strength of the concrete struts, the concrete strength depends on the width of the cracks developing at the shear-critical zone. Such width can be estimated on the same assumptions as for members without shear reinforcement $(w \propto \psi \cdot d)$. Thus, the crushing shear strength can be calculated as proportional to the punching shear strength of members without shear reinforcement (Figure A1b):

$$
\begin{aligned}
& V_{R}(\psi)=\lambda \cdot \frac{3}{4} \cdot \frac{b_{0, C S C T} \cdot d \cdot \sqrt{f_{c}}}{1+15 \cdot \frac{\psi \cdot d}{d_{g 0}+d_{g}}} \\
& V_{R}(\psi)=\lambda \cdot 9 \cdot \frac{b_{0, C S C r} \cdot d \cdot \sqrt{f_{c}}}{1+15 \cdot \frac{\psi \cdot d}{d_{g 0}+d_{g}}} \quad \text { [in.-lb units] }
\end{aligned}
$$


where $\lambda$ is a coefficient depending on the shear reinforcement system, which is proposed by Fernández-Ruiz and Muttoni ${ }^{3}$ to be 3.0 for studs or systems with perfect anchorage conditions (steel offcuts, headed reinforcement). For other systems, such as stirrups or where the reinforcement is developed by bond, a value $\lambda=2.5$ is adopted.

For the load-rotation behavior of the slab specimen and for both failure modes, a quadrilinear approach proposed by Muttoni (Equation 6 of Reference 23) has been selected to find the intersection point with the failure criteria.

$$
V=\frac{2 \pi}{r_{q}-r_{c}}\left(\begin{array}{l}
-m_{r} r_{0}+m_{R}\left\langle r_{y}-r_{0}\right\rangle+E I_{1} \psi\left\langle\ln \left(r_{1}\right)-\ln \left(r_{y}\right)\right\rangle+ \\
E I_{1} \chi_{T S}\left\langle r_{1}-r_{y}\right\rangle+m_{c r}\left\langle r_{c r}-r_{1}\right\rangle+E I_{0} \psi\left\langle\ln \left(r_{s}\right)-\ln \left(r_{c r}\right)\right\rangle
\end{array}\right)
$$

Operator $\langle\mathrm{x}\rangle$ is $\mathrm{x}$ for $\mathrm{x} \geq 0$ and 0 for $\mathrm{x}<0 . m_{r}$ is the radial moment per unit length acting in the slab portion at radius $=r_{0}$ and $m_{R}$ is the flexural strength. In determining $m_{R}$, the value of the yield strength of the reinforcement is considered, allowing thus to account for the influence of this parameter in the punching failure load. 
(a)

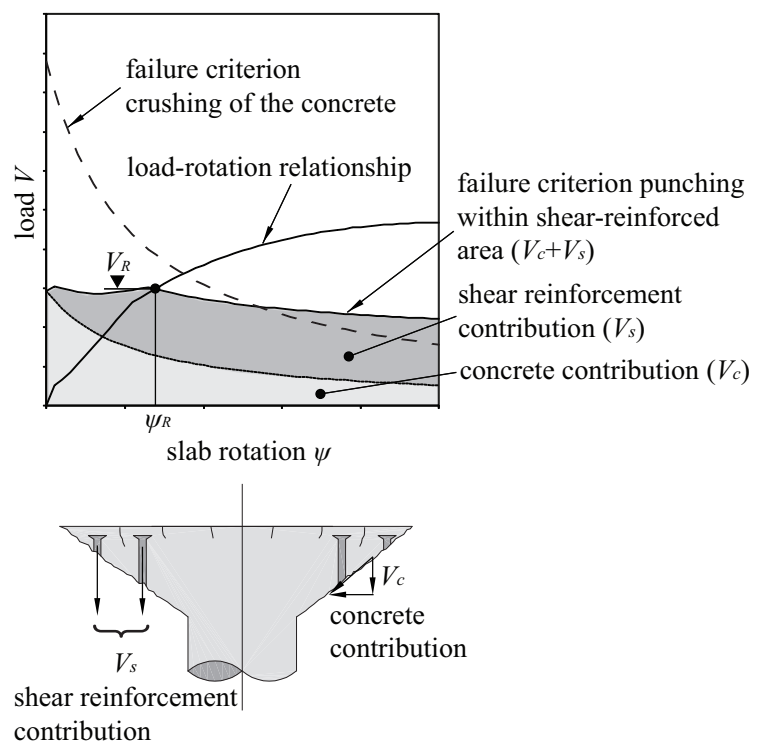

(b)

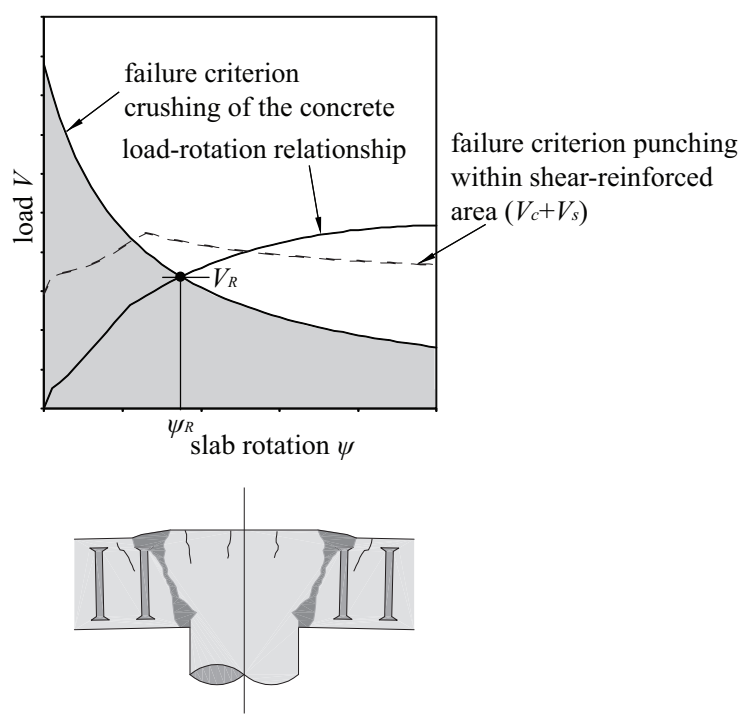

Fig. A1 - Load-rotation curve and failure criteria according to the $\mathrm{CSCT}^{2}$ : (a) punching within the shear-reinforced zone governing; and (b) crushing of concrete struts governing 


\section{Flexural strength ${ }^{4}$}

The flexural strength $V_{\text {flex }}$ of the slab specimens can be calculated based on the yield line theory leading to an expression for slabs reinforced and loaded as the test specimens presented herein (corresponding to a yield-line pattern as shown in Figure A2) of

$V_{\text {flex }}=\frac{8 m_{R}}{B-c} \cdot \frac{B^{2}-B \cdot c-c^{2} / 4}{B+b-2\left(c+b_{1}\right)}$

where $m_{R}$ is the nominal moment capacity, $B$ the side length of the slab specimen, $b$ the distance between the load introduction points, $b_{1}$ the distance of the load introduction points to the slab edge and $c$ the column size.

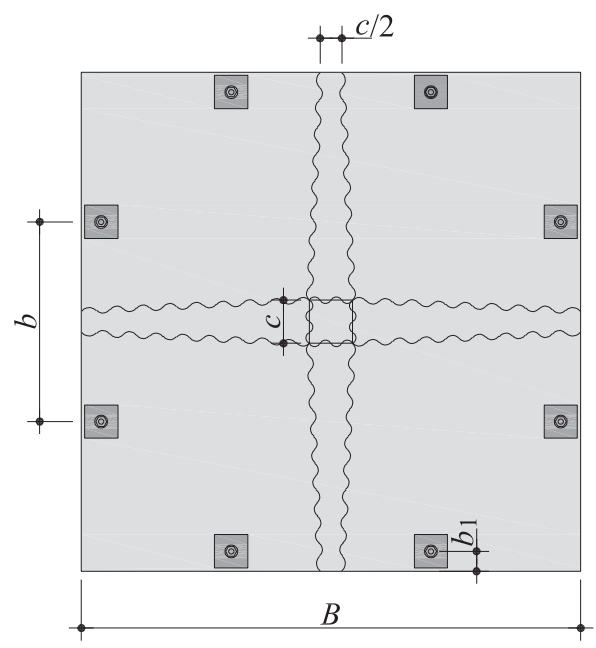

Fig. A2 - Yield-line pattern considered for the calculation of the flexural strength 